\title{
Lineage dynamics of the endosymbiotic cell type in the soft coral Xenia
}

https://doi.org/10.1038/s41586-020-2385-7

Received: 26 June 2019

Accepted: 28 April 2020

Published online: 17 June 2020

\section{Open access}

Check for updates

\author{
Minjie Hu ${ }^{1 凶}$, Xiaobin Zheng ${ }^{1}$, Chen-Ming Fan ${ }^{1 凶}$ \& Yixian Zheng ${ }^{1 凶}$
}

Many corals harbour symbiotic dinoflagellate algae. The algae live inside coral cells in a specialized membrane compartment known as the symbiosome, which shares the photosynthetically fixed carbon with coral host cells while host cells provide inorganic carbon to the algae for photosynthesis ${ }^{1}$. This endosymbiosis-which is critical for the maintenance of coral reef ecosystems-is increasingly threatened by environmental stressors that lead to coral bleaching (that is, the disruption of endosymbiosis), which in turn leads to coral death and the degradation of marine ecosystems ${ }^{2}$. The molecular pathways that orchestrate the recognition, uptake and maintenance of algae in coral cells remain poorly understood. Here we report the chromosome-level genome assembly of a Xenia species of fast-growing soft coral ${ }^{3}$, and use this species as a model to investigate coral-alga endosymbiosis. Single-cell RNA sequencing identified 16 cell clusters, including gastrodermal cells and cnidocytes, in Xenia sp. We identified the endosymbiotic cell type, which expresses a distinct set of genes that are implicated in the recognition, phagocytosis and/or endocytosis, and maintenance of algae, as well as in the immune modulation of host coral cells. By coupling Xenia sp. regeneration and single-cell RNA sequencing, we observed a dynamic lineage progression of the endosymbiotic cells. The conserved genes associated with endosymbiosis that are reported here may help to reveal common principles by which different corals take up or lose their endosymbionts.
Many corals take up dinoflagellate algae of the Symbiodiniaceae family into their gastrodermis through feeding. Some cells in the gastrodermis, which lines the digestive tract, may have the ability to recognize particular types of algae. Through phagocytosis and by modulating host immune responses, the matching algal type is enclosed by endomembranes to form symbiosomes inside coral cells ${ }^{1}$. The symbiosome membrane is believed to contain transporters that mediate nutrient exchange between the algae and host cells ${ }^{4}$. Comparative transcriptome analyses on whole organisms using different cnidarian species before and after algae colonization or bleaching have identified genes, the up- or downregulation of which could contribute to endosymbiosis ${ }^{5-7}$. Comparative genomic and transcriptomic information in endosymbiotic and non-symbiotic cnidarian species has also been used to search for genes that may have evolved to mediate the recognition or endocytosis of Symbiodiniacea $e^{6-9}$. However, these approaches do not differentiate whether the altered genes are expressed in the host endosymbiotic cells or other cell types without additional criteria. Protein inhibition or activation has also been used to suggest that host proteins containing C-type lectin domains, scavenger receptor domains or thrombospondin type 1 repeats are involved in uptake of algae and immunosuppression ${ }^{10-12}$. The broad expression and function of these proteins, coupled with potential off-target effects of inhibitors, greatly limit data interpretation. Therefore, a systematic description of genes and pathways that are selectively expressed in the host endosymbiotic cells is much needed to begin to understand the potential regulatory mechanisms that underlie the entry, establishment and-possibly-the expulsion of Symbiodiniaceae.

\section{Genome and single-cell transcriptome}

We chose to study a Xenia sp. of pulsing soft coral (Fig. 1a, b, Extended Data Fig. 1, Supplementary Video 1) that grows rapidly in a laboratory aquarium. Using Illumina short-read and Nanopore long-read sequencing (Extended Data Table 1), we assembled the Xenia genome into 556 high-quality contigs. Applying chromosome conformation capture (Hi-C $)^{13,14}$, we further assembled these contigs into 168 scaffolds; the longest 15 of these scaffolds contain $92.5 \%$ of the assembled genome of 222,699,500 bp, consistent with the GenomeScope estimation (Extended Data Fig. 2). To our knowledge, the Xenia genome has by far the longest scaffold length, and thus the most contiguous assembly, of the published cnidarian genomes (Fig. 1c). Annotation using several bulk RNA-sequencing (RNA-seq) datasets showed that Xenia sp. has 29,015 genes, similar to other cnidarians (Extended Data Tables 2,3). Consistent with previous phylogenetic analyse ${ }^{15}$, the octocorallians, Xenia sp.,Dendronephthya gigantea and Renilla reniformis are grouped as a clade that is sister to the hexacorallian clade (which contains sea anemones and scleractinian corals), as they are all anthozoans (Fig.1d).

We next performed single-cell RNA-seq (scRNA-seq) ${ }^{16}$ of whole polyps, stalks or tentacles using version 2 and version 3 chemistry of the 10x Genomics platform (Supplementary Table 1, Methods). Using $t$-distributed stochastic neighbour embedding $(t-\mathrm{SNE})^{17}$, we grouped the high-quality single-cell transcriptomes, covering 23,939 genes, into 16 cell clusters with distinct gene-expression patterns (Fig. 2a, b, Extended Data Fig. 3a, Supplementary Table 2). For validation, we

1Department of Embryology, Carnegie Institution for Science, Baltimore, MD, USA. ${ }^{凶}$ e-mail: mhu2@carnegiescience.edu; fan@carnegiescience.edu; zheng@carnegiescience.edu 

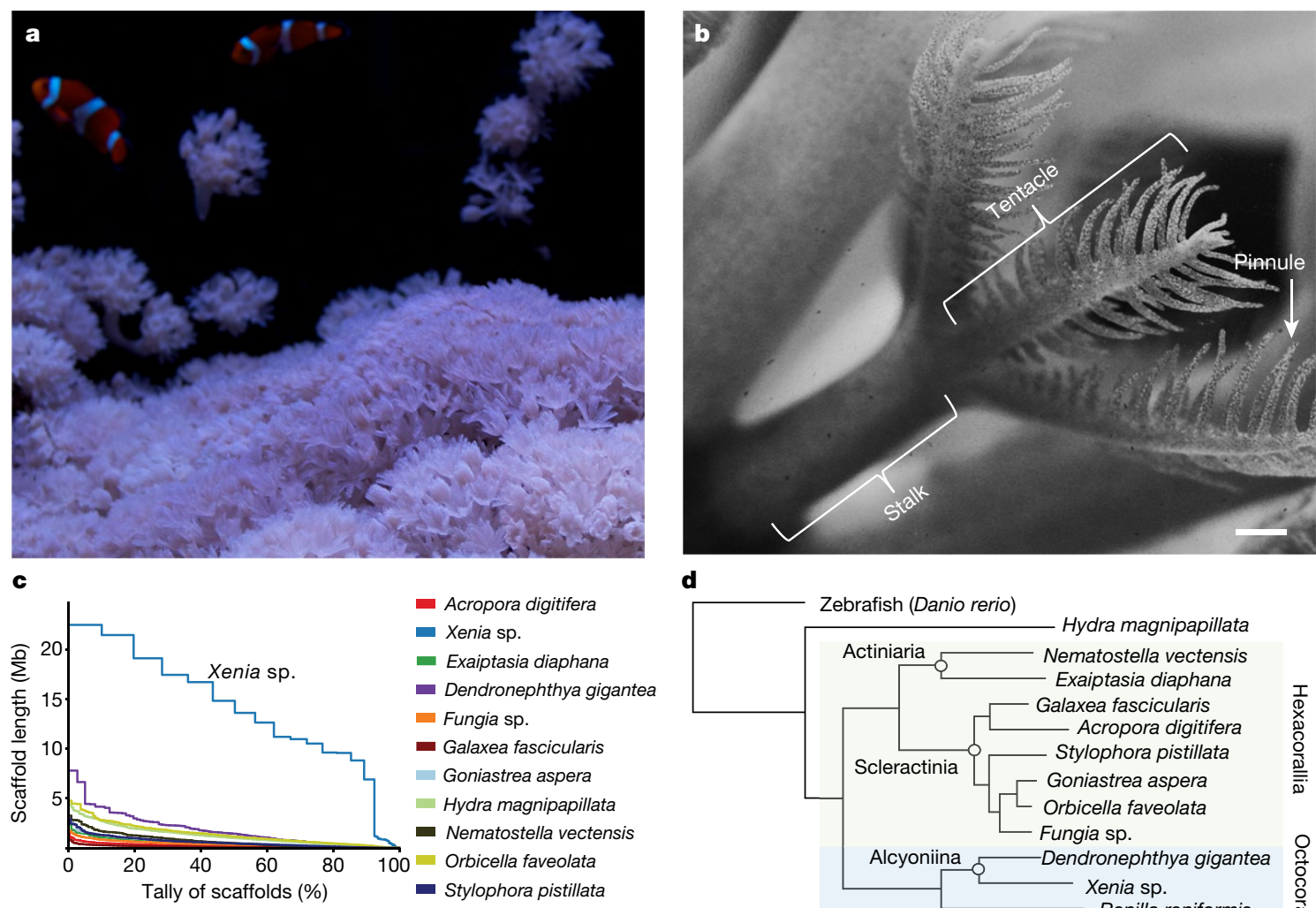

d

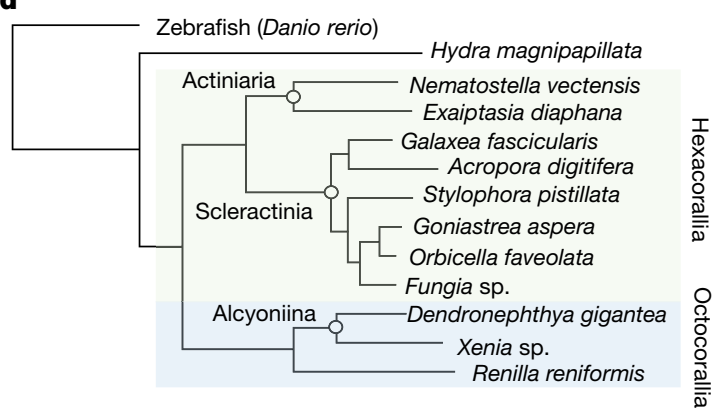

Fig. 1 High-quality genome assembly for Xenia sp. a, Xenia sp. grown in the laboratory aquarium. $\mathbf{b}$, An enlarged view of a Xenia sp. polyp with its main substructures indicated. Scale bar, $1 \mathrm{~mm}$.c, Comparisons of the assembled scaffold lengths ( $y$ axis) and tallies ( $x$ axis) of 11 sequenced cnidarians,

looked for two previously characterized cnidarian cells: the cnidocytes, which are used for prey capture and/or defence, and gastrodermal cells. The cells of cluster 11 express minicollagen and nematogalectin genes, which are markers of cnidocytes ${ }^{18-20}$ (Fig. 2c). Further analysis revealed that cluster 11 contained two subclusters (Fig. 2d, Extended Data Fig. 3b). Minicollagen genes are expressed in both subclusters, whereas nematogalectin genes are preferentially expressed in one (Fig. 2e, Extended Data Fig. 3c). RNA in situ hybridization (ISH) confirmed the expression of a nemetogalectin gene to be more spatially restricted than that of Minicollagen 1 in Xenia pinnules (Fig. $2 \mathrm{f}$, g, Extended Data Fig. 3d, e). Clusters 2, 12 and 16 express genes that encode collagens and proteases (Fig. $2 \mathrm{~h}$ ) that are known to be enriched in gastrodermis of Nematostella ${ }^{18}$. RNA ISH for Collagen 6, Astacin-like metalloendopeptidase 2 (both expressed by clusters 2 and 12 ) and the uncharacterized $\mathrm{Xe}$ _OO3623 gene (expressed by clusters 2,12 and 16 ) confirmed the high expression of these genes in the gastrodermis (Fig. $2 \mathrm{~h}-\mathrm{j}$, Extended Data Fig. $3 \mathrm{f}-\mathrm{i}$ ). Thus, the clustering analyses and ISH identified cnidocytes and cells in the gastrodermis in Xenia.

\section{Endosymbiotic cell type in Xenia sp.}

To identify the cells that performendosymbiosis, we took advantage of the autofluorescence of the member of theSymbiodiniaceae (Durusdinium) in our Xenia sp. (Methods). Using fluorescence-activated cell sorting (FACS), we separated alga-containing and alga-free Xenia cells (Fig. 3a,b) and performed bulk RNA-seq (Supplementary Table 3). By comparing these bulk transcriptomes with genes expressed in each cluster, we found that cells of cluster 16 exhibited the highest overall similarity to the alga-containing cells and most of the marker genes for cluster 16 (Supplementary Table 4) have a higher level of expression in alga-containing Xenia cells than that

including Xenia sp.d, Evolutionary comparisons of Xenia sp. with other cnidarians, as indicated. Zebrafish and $H y d r a$ were used as outgroups. The phylogenetic branch points were assigned with $100 \%$ confidence.

in alga-free Xenia cells (Fig. 3c, d, Supplementary Table 5). RNAscope ISH for two of the cluster-16 marker genes-one of which encodes a protein with lectin and kazal protease inhibitor domains (abbreviated LePin, encoded by a gene that we name LePin), and the other of which encodes Granulin 1-showed that these genes were expressed in alga-containing gastrodermal cells (Fig. 3e, f, Extended Data Fig. 4a, b). Additionally, on average $95 \%$ and $98 \%$ of alga-containing Xenia cells were positive for expression of LePin and Granulin 1, respectively (Extended Data Fig. 4c). On the basis of microscopy of cryopreserved tissue sections or FACS analyses, we estimated that on average $2-6 \%$ of Xenia cells contained algae and that tentacles have a higher percentage of alga-containing cells than do stalks (Extended Data Fig. 4d, Methods). This is consistent with the cluster-16 endosymbiotic cells being identified by scRNA-seq as a small fraction ( 382 cells, $1.4 \%$ of the total). Of the three gastrodermal cell clusters, cluster- 16 cells therefore have a high likelihood of being a major cell type involved in endosymbiosis.

Among the top 89 marker genes enriched in the cluster-16 endosymbiotic cells, 67 encode proteins with domains of known or predicted functions, including receptors, extracellular matrix proteins, immune response proteins, phagocytosis and/or endocytosis proteins, or nutrient transporters (Extended Data Fig. 4e, Supplementary Table 4). Three proteins-encoded by CD36,DMTB1 and CUZD1-contain CD36 or scavenger receptor domains that are known to recognize a wide range of microbial surface ligands and mediate their phagocytosis, and that also modulate the innate immune response of the host ${ }^{11,21,22}$ (Fig. 3g, Extended Data Fig. 5a). CUZD1 is the least understood, and is similar to DMBT1 in domain organization. DMBT1 functions in pattern recognition of microorganisms. In mammals, it is expressed on the surface of the gastrointestinal tract, where it recognizes polysulfated and polyphosphorylated ligands on microorganisms, represses the 


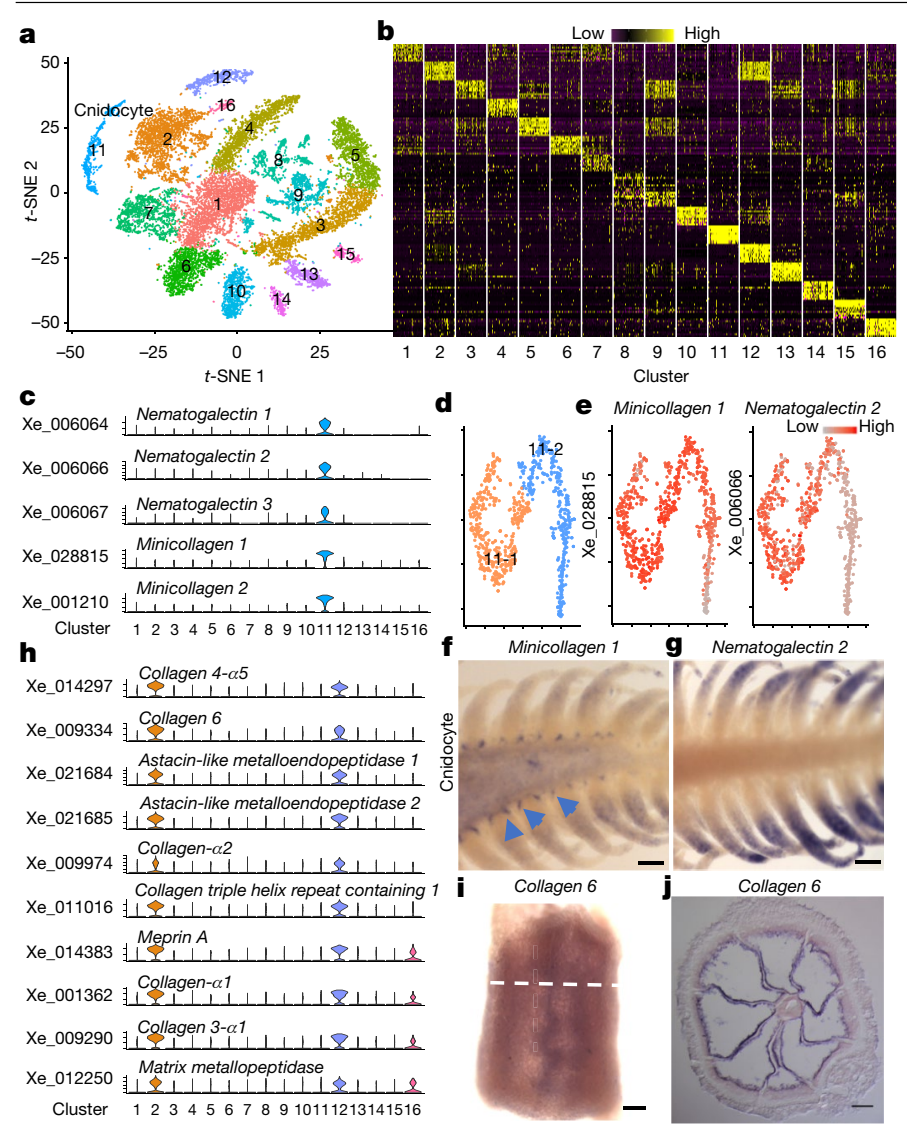

Fig. 2 | scRNA-seq transcriptomes suggest that there are 16 cell types in Xenia sp. a, Transcriptomes of 19,134 individual Xenia sp. cells obtained by scRNA-seq were grouped into 16 clusters (colour-coded) and presented in $t$-SNE space. Each coloured dot represents one cell.b, Gene-expression heat map (scale at the top) for the top 10 gene markers that define each cluster. Each column represents one cell cluster, and each row represents one gene. Forty cells were randomly selected from each of the 16 cell clusters for plotting. c, Expression profiles of the indicated cluster-11 Xenia (Xe) marker genes out of all cell clusters. $\mathbf{d}$, Cluster-11 cells are subdivided into two populations (11-1, 423 cells; $11-2,374$ cells, colour-coded) and displayed in a $t$-SNE space. Each coloured dot represents a cell. e, Expression levels (scale to the top right) of two cluster-11 markers, Minicollagen 1 and Nematogalectin 2, are shown in a $t$-SNE plot. $n=797$ cells. $\mathbf{f}, \mathbf{g}$, Whole-mount RNA ISH of Minicollagen 1 (f) and Nematogalectin 2 (g), showing their expression in tentacles. Arrows indicate the expression of Minicollagen 1 at the base of pinnules. $\mathbf{h}$, Expression profiles of marker genes enriched in clusters 2,12 and 16 out of all 16 clusters. $\mathbf{i}, \mathbf{j}$, RNA ISH of Collagen 6. Whole-mount view of the stalk in $\mathbf{i}$ and cross-section image in j. The white dashed line in indicates the cross-section level inj. More than 12 polyps from 4 independent experiments were used for each probe. Scale bars, $100 \mu \mathrm{m}(\mathbf{f}, \mathbf{g}, \mathbf{j}), 150 \mu \mathrm{m}$ (i). Cell numbers for clusters $1-16$ are 2,794; 2,704; 2,073; 1,679; 1,511;1,374;1,248;1,069; 986; 923; 797; 649; 575;321; 246; and 185, respectively (a, c, h).

inflammatory response and regulates the differentiation of gastrointestinal cells ${ }^{23}$. LePin and Granulin 1, which we used for ISH, have homologues in Exaiptasia, as well as stony and soft corals. Because LePin has an $\mathrm{N}$-terminal signal peptide followed by multiple domains (including $\mathrm{H}$ - and $\mathrm{C}$-type lectins and a Kazal-type serine protease inhibitor) (Extended Data Fig. 5b), it may confer selectivity for the Symbiodiniaceae. On the basis of previous studies of granulins in mammals ${ }^{24}$, Granulin 1 may modulate the immune response in Xenia endosymbiotic cells.

Phagocytosis of the Symbiodiniaceae by gastrodermal cells (which are of a similar size to these algal cells) requires substantial expansion of the host cell, but the genes that regulate this size expansion
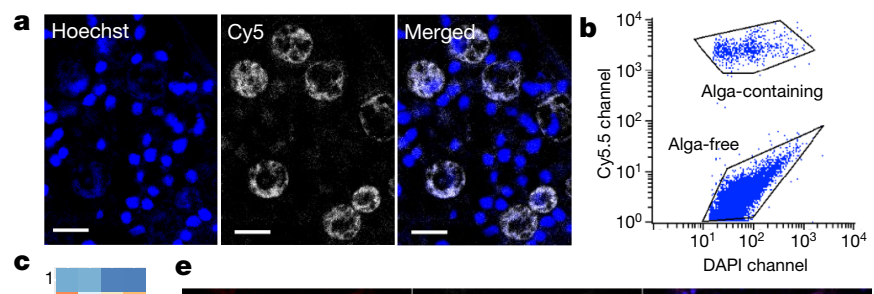

c DAPI channel
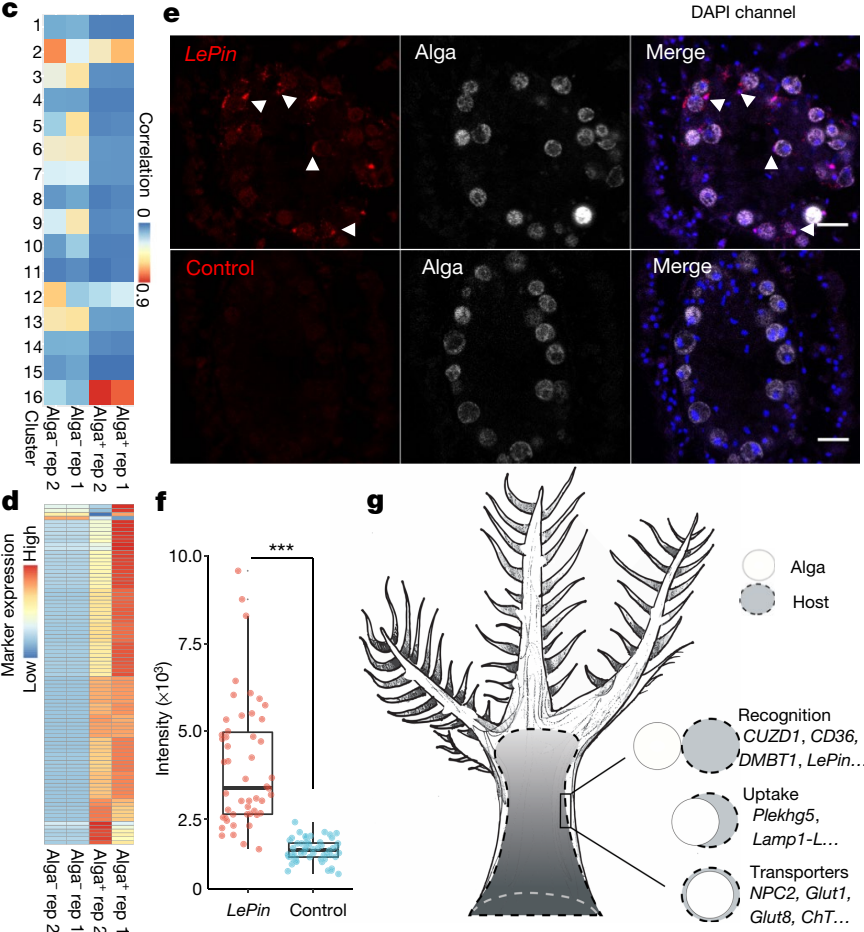

Fig. 3 | Identification of genes specifically expressed in Xenia sp. endosymbiotic cells. a, The endosymbiotic algae in Xenia display autofluorescence in the Cy5.5 far-red channel. A cross-section of Xenia, with the Xenia and algal nuclei stained by Hoechst (blue) and alga autofluorescence (white).b, A FACS profile of dissociated live Xenia cells using Cy5.5 and DAPI channels. Five biological replicates $(\mathbf{a}, \mathbf{b})$.c, Pearson correlation of gene expression between the scRNA-seq data of 16 cell clusters and the bulk RNA-seq data of 2 biological replicates of FACS-isolated alga-containing (alga ${ }^{+}$rep 1 and alga $^{+}$rep 2) and alga-free (alga ${ }^{-}$rep 1 and alga ${ }^{-}$rep 2) cells. d, Heat map showing the expression levels of the 89 marker genes for cluster-16 cells in alga-containing and alga-free cells, isolated by FACS. e, Ultra-sensitive fluorescence RNA ISH by RNAscope probing for LePin (red) (top) and control (bottom). White arrows indicate the LePin signal. Hoechst staining of all nuclei is shown in blue. Scale bars, $20 \mu \mathrm{m}$.f, Quantification of LePin signals. The fluorescence signal surrounding each alga is quantified in random sections and plotted (a dot $=$ a section) for LePin and controls. ${ }^{* * *} P=2.84 \times 10^{-16}$, two-sided $t$-test. Lines in the box denote the median; the upper and lower edges of the box represent the upper and lower quartiles, respectively. Nine polyps from three independent experiments were used for each probe $(\mathbf{e}, \mathbf{f})$. g, Illustration of steps through which Xenia endosymbiotic cells may recognize and take up algae to establish endosymbiosis, with some candidate genes shown at each step.

are unknown. Among the endosymbitoic marker genes that we found, Plekhg5 encodes a highly conserved RhoGEF (Fig. 3g, Extended Data Fig. 5c). In Xenopus, Plekhg5 localizes to the apical membrane of epithelial cells and recruits actomyosin to induce cell elongation and apical constriction $^{25}$. Thus, Plekhg5 is a prime candidate for regulating the extension of the apical membrane to engulf algae of the Symbiodiniaceae during the early stages of phagocytosis in Xenia. Upon phagocytosis, algae of the Symbiodiniaceae are enclosed by the host membrane to form symbiosomes ${ }^{26}$. Although the symbiosome is acidified similarly 
to lysosomes ${ }^{27}$, the genes that are involved in the formation of the symbiosome remain unclear. Xenia sp. has two genes that encode lysosome-associated membrane glycoproteins, which are more similar to the previously characterized LAMP1 than to LAMP2 ${ }^{28}$. In Xenia, Lamp1-L encodes a larger protein and is an endosymbiotic marker gene, whereas Lamp1-S encodes a smaller protein and is expressed across all cell clusters (Extended Data Fig. 5d, e). Because lysosome-associated membrane glycoproteins are known to regulate phagocytosis, endocytosis, lipid transport and autophagy ${ }^{28}$, Lamp1-L may regulate symbiosome formation and/or function (Fig. $3 \mathrm{~g}$ ). Several endosymbiotic marker genes encode enzymes that may promote the establishment of endosymbiosis or facilitate nutrient exchanges between alga and the host cell. For example, there are 17 genes that potentially participate in nutrient exchanges, as they encode transporters for sugar, amino acids, ammonium, water, cholesterol and choline (Fig. 3g, Extended Data Fig. 4e, Supplementary Table 4).

\section{Lineage dynamics of endosymbiotic cells}

To better understand the temporal dynamics of cluster- 16 cells, we developed a Xenia regeneration model. We surgically cut away all tentacles from Xenia polyps and found that the stalks regenerated all tentacles in several days when cultured in the seawater from our aquarium that houses stock corals (Fig. 4a). Individual tentacles also regenerated into full polyps, but required a longer time (data not shown). BrdU labelling showed that some proliferated $\left(\mathrm{BrdU}^{+}\right)$gastrodermal cells began to take up algae that were present either in the gastrodermis or in the seawater at day 4 of regeneration (Extended Data Fig. 6a, b). We performed scRNA-seq of the regenerating stalks and pooled the data with the scRNA-seq of non-regenerating samples (Methods).

We used Monocle 2 to perform pseudotemporal ordering of all of the endosymbiotic Xenia cells ${ }^{29}$ (Fig. 4b); Monocle 2 uses reversed graph embedding to construct a principal curve that passes through the middle of the cells in the $t$-SNE space. Because this trajectory analysis does not provide a direction of cell-state progression, we used velocyto ${ }^{30}$ to determine the directionality of lineage progression of all cells and focused on the endosymbiotic cells in the regenerating sample. Velocyto calculates RNA velocity by comparing the number of unspliced and spliced reads, which measures the expected change in gene expression in the near future-thereby providing the directionality of cell-state change. This enabled the identification of early and late stages of endosymbiotic cells (green and red, respectively, in Extended Data Fig. 6c). The cell trajectory showed that the early and late-stage cells are mapped to relatively early and late pseudotime, respectively (Extended Data Fig. 6d). Thus, the pseudotime represents actual lineage progression. Modelling of gene expression revealed substantial changes along pseudotime. Further hierarchical clustering showed distinct gene-expression patterns, which helped to define five putative endosymbiotic cell states (Fig. 4c, Supplementary Table 6).

To further explore the cell dynamics in these five states, we compared single-cell transcriptomes to transcriptomes from the bulk RNA-seq of alga-containing or alga-free cells isolated by FACS, and plotted the expression correlation along pseudotime. State- 3 cells showed the strongest correlation with the alga-containing cells, followed by state 2 and then state 1 ; state- 4 and state- 5 cells showed the least correlation (Fig. 4d). This suggests that state 3 represents mature, alga-containing cells. State- 1 and state- 5 cells showed correlations with alga-free cells (Fig. 4d). Given that these five states are present in our identified endosymbiotic cell type with a linear pseudotime progression, we hypothesize that state-1 cells are pre-endosymbiotic progenitors that can transition through state 2 to become state- 3 mature alga-containing cells, and that state-3 cells could further transit through state 4 into state- 5 post-endosymbiotic cells (Fig. 4e). In support of this, we found that the regenerating samples have higher percentages

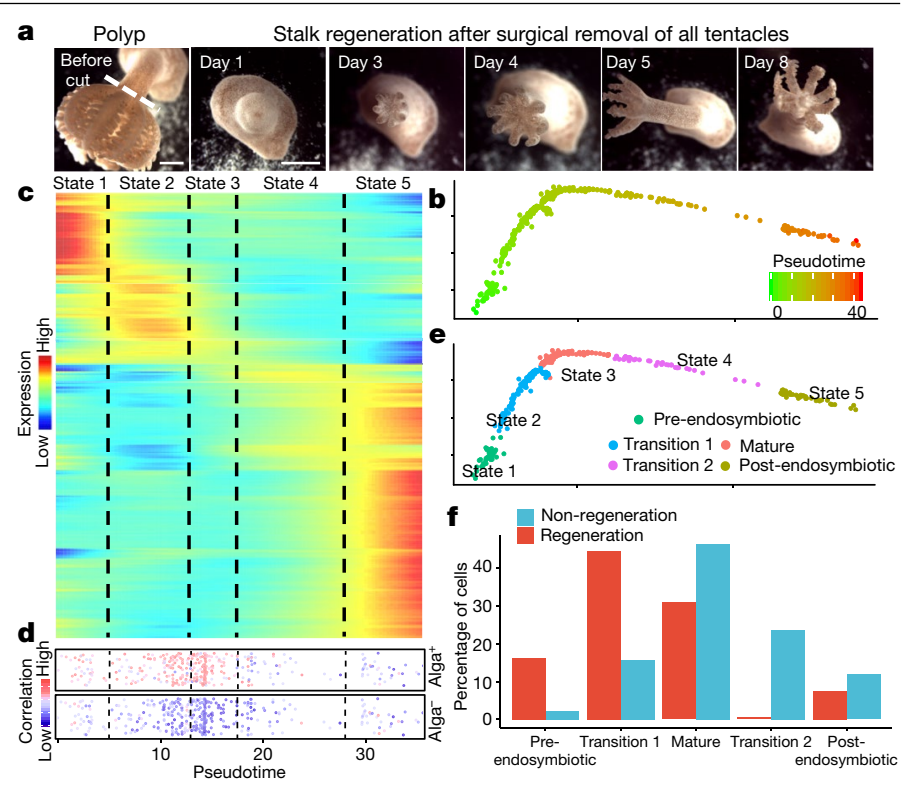

Fig. 4 | Dynamic lineage progression of endosymbiotic cells. a, An example of a Xenia sp. polyp (shown in the panel on the far left) is surgically cut at the white dashed line to remove all the tentacles. A surgically cut stalk is shown to regenerate in successive days as indicated. Five biological replicates. Scale bars, $1 \mathrm{~mm}$. b, Pseudotime trajectory of all endosymbiotic cells (a dot represents a cell) identified in regeneration and non-regeneration scRNA-seq datasets. The pseudotime indicator is shown at the bottom right.c, Heat map for gene-expression levels along pseudotime.d, Correlation of the scRNA-seq transcriptome with the bulk RNA-seq transcriptome of alga-containing or alga-free Xenia cells, isolated by FACS. The endosymbiotic cells used to model gene expression along the pseudotime line are aligned with the heat map. Each cell represented by a dot is coloured according to the Pearson correlation of its transcriptome with the indicated bulk RNA-seq transcriptome. Five cell states (states 1-5, separated by dashed lines) are defined by differential gene expression together with the Pearson correlation. e, Five states defined by c and $\mathbf{d}$.f, The percentage of cells in each state in regeneration and non-regeneration samples.

of state- 1 (pre-endosymbiotic) and state-2 (transition 1 ) cells, and that the non-regeneration sample has more state-3 mature, state-4 (transition 2) and state-5 (post-endosymbiotic) cells (Fig. 4f).

We further verified our hypothetical endosymbiotic cell states in the regeneration paradigm by pulse-chase experiments (Methods). After cutting, Xenia sp. stalks were pulsed with EdU at day 3 and day 4 of regeneration. EdU was washed out, corals were allowed to continue regenerating and samples were collected at days 7, 9,11,13,15,17 and 19 (Extended Data Fig. 7a). Using FACS (Extended Data Fig. 7b-h), we calculated the percentages of $\mathrm{EdU}^{+}$alga-containing cells out of all alga-containing Xenia cells, and the percentages of all alga-containing Xenia cells out of all Xenia cells. We found an increase of $\mathrm{EdU}^{+}$alga-containing Xenia cells up to regeneration day 13 , which may account for the increase in uptake of algae during tentacle growth (as tentacles have more alga-containing cells than the stalk) (Extended Data Figs. 4d, 7i). Thereafter, the percentage of total alga-containing cells remained constant, but the percentage of $\mathrm{EdU}^{+}$alga-containing cells gradually decreased (Extended Data Fig. 7i,j). Thus, these results support our hypothesis that the endosymbiotic cells progress from a progenitor state through an alga-uptake state and a mature alga-containing state, followed by loss of their algae.

Analysis of differentially expressed genes suggests the roles of each state in endosymbiotic cell lineage development and function. For example, the state-1 pre-endosymbiotic cells express $W N T 7 b$ and WNT11, which may regulate progenitor-cell proliferation and differentiation through the Wnt signalling pathway ${ }^{31,32}$. Among 24 genes 


\section{Article}

preferentially expressed in state 3,13 are endosymbiotic markers that are expressed at higher levels in the FACS-isolated alga-containing Xenia cells than that in the alga-free cells. By contrast, none of the genes preferentially expressed in state 5 is an endosymbiotic marker. Instead, state- 5 cells preferentially express several oxidative-stress-response genes (see Supplementary Table 6 for detailed descriptions). Because increased oxidative stress is observed upon cellular ageing and during coral bleaching ${ }^{33-35}$, state-5 cells may represent a natural ageing state of endosymbiotic cells that are no longer able to hold on to their algae. Additional molecular studies exploring the function of the differentially expressed genes in each state are needed to further validate our five-state hypothesis.

\section{Summary and outlook}

Here we demonstrate the power of genomic and bioinformatic tools in studying coral biology. The Xenia sp. genome encodes essential components of RNA interference, such as Dicer and Ago, and DNA repair pathway proteins, which should enable the development of gene-manipulation tools to determine the mechanism of endosymbiosis. Although we focused on studying the endosymbiotic cell lineage, the regenerative processes for the other cell clusters can be similarly investigated in future analyses. Our studies suggest that Xenia endosymbiotic cells exist in five progressive states that are dynamic between homeostatic conditions and the regeneration process (Fig. 4f). It will be important to further understand the endosymbiotic lineage progression under different environmental stressors and to test whether efficient recovery from bleaching relies on state-1 pre-endosymbiotic cells. It is also feasible to test whether forced regeneration by fragmenting bleached corals can stimulate the expansion of state-1 pre-endosymbiotic cells and the restoration of endosymbiosis.

\section{Online content}

Any methods, additional references, Nature Research reporting summaries, source data, extended data, supplementary information, acknowledgements, peer review information; details of author contributions and competing interests; and statements of data and code availability are available at https://doi.org/10.1038/s41586-020-2385-7.

1. Davy, S. K., Allemand, D. \& Weis, V. M. Cell biology of cnidarian-dinoflagellate symbiosis Microbiol. Mol. Biol. Rev. 76, 229-261 (2012).

2. Putnam, H. M., Barott, K. L., Ainsworth, T. D. \& Gates, R. D. The vulnerability and resilience of reef-building corals. Curr. Biol. 27, R528-R540 (2017).

3. McFadden, C. S. Reynolds, A. M. \& Janes, M. P. DNA barcoding of xeniid soft corals (Octocorallia: Alcyonacea: Xeniidae) from Indonesia: species richness and phylogenetic relationships. Syst. Biodivers. 12, 247-257 (2014).

4. Sproles, A. E. et al. Phylogenetic characterization of transporter proteins in the cnidariandinoflagellate symbiosis. Mol. Phylogenet. Evol. 120, 307-320 (2018).

5. Matthews, J. L. et al. Optimal nutrient exchange and immune responses operate in partner specificity in the cnidarian-dinoflagellate symbiosis. Proc. Natl Acad. Sci. USA 114, 13194-13199 (2017)

6. Yuyama, I., Ishikawa, M., Nozawa, M., Yoshida, M. A. \& Ikeo, K. Transcriptomic changes with increasing algal symbiont reveal the detailed process underlying establishment of coral-algal symbiosis. Sci. Rep. 8, 16802 (2018).

7. Pinzón, J. H. et al. Whole transcriptome analysis reveals changes in expression of immune-related genes during and after bleaching in a reef-building coral. $R$. Soc. Open Sci. 2, 140214 (2015).

8. Wolfowicz, l. et al. Aiptasia sp. larvae as a model to reveal mechanisms of symbiont selection in cnidarians. Sci. Rep. 6, 32366 (2016).

9. Lehnert, E. M. et al. Extensive differences in gene expression between symbiotic and aposymbiotic cnidarians. G3 (Bethesda) 4, 277-295 (2014).
10. Neubauer, E. F. et al. A diverse host thrombospondin-type-1 repeat protein repertoire promotes symbiont colonization during establishment of cnidarian-dinoflagellate symbiosis. eLife 6, e24494 (2017).

11. Neubauer, E. F., Poole, A. Z., Weis, V. M. \& Davy, S. K. The scavenger receptor repertoire in six cnidarian species and its putative role in cnidarian-dinoflagellate symbiosis. Peer $\mathbf{4}$ e2692 (2016).

12. Wood-Charlson, E. M., Hollingsworth, L. L., Krupp, D. A. \& Weis, V. M. Lectin/glycan interactions play a role in recognition in a coral/dinoflagellate symbiosis. Cell. Microbiol. 8, 1985-1993 (2006)

13. Zheng, X. et al. Lamins organize the global three-dimensional genome from the nuclear periphery. Mol. Cell 71, 802-815 (2018).

14. Dudchenko, O. et al. De novo assembly of the Aedes aegypti genome using Hi-C yields chromosome-length scaffolds. Science 356, 92-95 (2017).

15. Kayal, E. et al. Phylogenomics provides a robust topology of the major cnidarian lineages and insights on the origins of key organismal traits. BMC Evol. Biol. 18, 68-86 (2018).

16. Chen, G., Ning, B. \& Shi, T. Single-cell RNA-seq technologies and related computational data analysis. Front. Genet. 10, 317 (2019).

17. Herring, C. A., Chen, B., McKinley, E. T. \& Lau, K. S. Single-cell computational strategies for lineage reconstruction in tissue systems. Cell. Mol. Gastroenterol. Hepatol. 5, 539-548 (2018).

18. Sebe-Pedros, A. et al. Cnidarian cell type diversity and regulation revealed by whole-organism single-cell RNA-seq. Cell 173, 1520-1534 (2018).

19. Hwang, J. S. et al. Nematogalectin, a nematocyst protein with GlyXY and galectin domains, demonstrates nematocyte-specific alternative splicing in Hydra. Proc. Natl Acad. Sci. USA 107, 18539-18544 (2010).

20. David, C. N. et al. Evolution of complex structures: minicollagens shape the cnidarian nematocyst. Trends Genet. 24, 431-438 (2008).

21. Silverstein, R. L., Li, W., Park, Y. M. \& Rahaman, S. O. Mechanisms of cell signaling by the scavenger receptor CD36: implications in atherosclerosis and thrombosis. Trans. Am. Clin. Climatol. Assoc. 121, 206-220 (2010).

22. Kang, W. \& Reid, K. B. DMBT1, a regulator of mucosal homeostasis through the linking of mucosal defense and regeneration? FEBS Lett. 540, 21-25 (2003).

23. End, C. et al. DMBT1 functions as pattern-recognition molecule for poly-sulfated and poly-phosphorylated ligands. Eur. J. Immunol. 39, 833-842 (2009).

24. Cenik, B., Sephton, C. F., Kutluk Cenik, B., Herz, J. \& Yu, G. Progranulin: a proteolytically processed protein at the crossroads of inflammation and neurodegeneration. J. Biol. Chem. 287, 32298-32306 (2012).

25. Popov, I. K., Ray, H. J., Skoglund, P., Keller, R. \& Chang, C. The RhoGEF protein Plekhg5 regulates apical constriction of bottle cells during gastrulation. Development 145, dev168922 (2018).

26. Meyer, E. \& Weis, V. M. Study of cnidarian-algal symbiosis in the "omics" age. Biol. Bull. 223, 44-65 (2012).

27. Barott, K. L., Venn, A. A., Perez, S. O., Tambutté, S. \& Tresguerres, M. Coral host cells acidify symbiotic algal microenvironment to promote photosynthesis. Proc. Natl Acad. Sci. USA 112, 607-612 (2015)

28. Alessandrini, F., Pezzè, L. \& Ciribilli, Y. LAMPs: shedding light on cancer biology. Semin. Oncol. 44, 239-253 (2017).

29. Trapnell, C. et al. The dynamics and regulators of cell fate decisions are revealed by pseudotemporal ordering of single cells. Nat. Biotechnol. 32, 381-386 (2014).

30. La Manno, G. et al. RNA velocity of single cells. Nature 560, 494-498 (2018).

31. Afelik, S., Pool, B., Schmerr, M., Penton, C. \& Jensen, J. Wnt7b is required for epithelial progenitor growth and operates during epithelial-to-mesenchymal signaling in pancreatic development. Dev. Biol. 399, 204-217 (2015)

32. O'Brien, L. L. et al. Wnt11 directs nephron progenitor polarity and motile behavior ultimately determining nephron endowment. eLife 7, e40392 (2018).

33. Downs, C. A. et al. Oxidative stress and seasonal coral bleaching. Free Radic. Biol. Med. 33, 533-543 (2002).

34. Mydlarz, L. D. \& Jacobs, R. S. An inducible release of reactive oxygen radicals in four species of gorgonian corals. Mar. Freshwat. Behav. Physiol. 39, 143-152 (2006)

35. Finkel, T. \& Holbrook, N. J. Oxidants, oxidative stress and the biology of ageing. Nature 408, 239-247 (2000).

Publisher's note Springer Nature remains neutral with regard to jurisdictional claims in published maps and institutional affiliations.

Open Access This article is licensed under a Creative Commons Attribution 4.0 International License, which permits use, sharing, adaptation, distribution and reproduction in any medium or format, as long as you give appropriate credit to the original author(s) and the source, provide a link to the Creative Commons license, and indicate if changes were made. The images or other third party material in this article are included in the article's Creative Commons license, unless indicated otherwise in a credit line to the material. If material is not included in the article's Creative Commons license and your intended use is not permitted by statutory regulation or exceeds the permitted use, you will need to obtain permission directly from the copyright holder. To view a copy of this license, visit http://creativecommons.org/licenses/by/4.0/.

(c) The Author(s) 2020 


\section{Methods}

No statistical methods were used to predetermine sample size. The experiments were not randomized and investigators were not blinded to allocation during experiments and outcome assessment other than the bioinformatic analyses.

\section{Coral aquarium}

The coral aquarium is established in a tank (Reefer 450 system, Red Sea). The artificial seawater, made from Coral Pro Salt (Red Sea), was first incubated with live rocks for two months before introducing Xenia sp., other corals, fish, snails and hermit crabs. The aquarium is maintained at about $80^{\circ} \mathrm{F}$ with about $25 \%$ change of seawater every 1-2 weeks. The light is provided by Hydra 26 HD LED (Aqua Illumination) with $60 \%$ power on during 10:00 to 19:00. The fish were fed with fish pellets (New Life Spectrum Marine Fish Formula) and Green Marine Algae (Ocean Nutrition).

The Xenia sp. was obtained from a local coral aquarium shop called CTE Aquatics. We performed taxonomy analysis by amplifying ITS2 rDNA region of Symbiodiniaceae species with primers (SYM VAR 5.8S2, GAATTGCAGAACTCCGTGAACC and SYM_VAR_REV, CGGGTTCWCTTGT YTGACTTCATGC) ${ }^{36}$. Sequence analysis showed that the Xenia sp. in our aquarium contains multiple Symbiodiniaceae species, of the genus Durusdinium. In all of our experiments, samples of polyps or colonies were randomly selected from the aquarium. We selected polyps that appeared fully grown in size, and colonies that were easy to break off from their attachment sites. We will share our live Xenia sp. with any researchers upon request. We have also deposited some frozen and fixed coral colonies, along with genomic DNA and total RNA, at the Smithsonian National Museum of Natural History (catalogue no., USNM 1613385).

\section{Genomic DNA isolation from Xenia sp.}

To enable Nanopore DNA sequencing, we modified a protocol ${ }^{37}$ that allowed the isolation of long DNA fragments. For each DNA preparation, one or two Xenia sp. colonies containing about 30 polyps were collected from the aquatic tank and washed 3 times for 5 min each with $\mathrm{Ca}^{2+}$ - and $\mathrm{Mg}^{2+}$-free artificial seawater $(449 \mathrm{mM} \mathrm{NaCl}, 9 \mathrm{mM} \mathrm{KCl}$, $33 \mathrm{mM} \mathrm{Na}_{2} \mathrm{SO}_{4}, 2.15 \mathrm{mM} \mathrm{NaHCO}_{3}, 10 \mathrm{mM}$ Tris-HCl, $2.5 \mathrm{mM}$ EGTA, pH 8.0). Tentacles were cut away, as they secrete a lot of mucus (which affected the quality of the isolated DNA). The remaining stalks and the bases of individual Xenia colonies were placed in $100 \mu \mathrm{l}$ DNAzol (Invitrogen) in a $1.5-\mathrm{ml}$ microcentrifuge tube. The tissues were cut into small pieces by a scissor to make fragment sizes of about $1 / 10$ th of the original size. These fragments were further minced by a small pestle made for 1.5-ml microcentrifuge tubes (Fisher Scientific, 12-141-364). Then, $900 \mu \mathrm{l}$ DNAzol was added, followed by vortexing the sample and then transferred to a 15-ml conical tube. Four millilitres of DNAzol and $50 \mu \mathrm{l}$ of $10 \mathrm{mg} / \mathrm{ml} \mathrm{RNase} A$ were then added to the tube and mixed, followed by incubation at $37^{\circ} \mathrm{C}$ for $10 \mathrm{~min}$. Then, $25 \mu \mathrm{l} \mathrm{of} 20 \mathrm{mg} / \mathrm{ml}$ proteinase $\mathrm{K}$ was then added, mixed and the tube was incubated at $37^{\circ} \mathrm{C}$ for another $10 \mathrm{~min}$. The sample was centrifuged at 5,000 $\mathrm{g}$ for $10 \mathrm{~min}$. The supernatant was transferred to another 15-ml tube. After adding $2.5 \mathrm{ml}$ ethanol, the tube was gently mixed by inverting several times. The tube was left to stand at room temperature for $3 \mathrm{~min}$ followed by centrifugation at $1,000 \mathrm{~g}$ for $10 \mathrm{~min}$ to pellet the DNA. The supernatant was discarded and the DNA pellet was resuspended in $500 \mu \mathrm{ITE}(10 \mathrm{mM}$ Tris- $\mathrm{HCl}, 1 \mathrm{mM}$ disodium EDTA, $\mathrm{pH}$ 8.0). After the DNA had dissolved, $500 \mu \mathrm{l}$ of phenol:chloroform:isoamyl alcohol (25:24:1) was added, and the tube was placed on the Intelli-Mixer RM-2S for mixing using programme $\mathrm{C} 1$ at $35 \mathrm{rpm}$ for $10 \mathrm{~min}$. The mixture was then transferred to a 2-ml phase-lock gel (QuantaBio, Cat. 2302820) and centrifuged at $4,500 \mathrm{rpm}$ for $10 \mathrm{~min}$. The aqueous phase was transferred into a new 2-ml tube, $200 \mu \mathrm{l} 5 \mathrm{M}$ ammonium acetate and $1.5 \mathrm{ml}$ ice-cold ethanol were added followed by centrifugation at $10,000 \mathrm{~g}$ for $10 \mathrm{~min}$ to pellet DNA. The pellet was washed twice with $1 \mathrm{ml} 80 \%$ ethanol. After removing as much ethanol as possible, the DNA pellet was left to dry at $42^{\circ} \mathrm{C}$ for $1 \mathrm{~min}$, and then resuspended in $50 \mu \mathrm{l} \mathrm{TE}$ buffer.

\section{Illumina sequencing}

Genomic DNA prepared as in 'Genomic DNA isolation from Xenia sp.' was fragmented into about $400 \mathrm{bp}$, and libraries were made with ThruPLEX DNA-Seq kit (TaKaRa) according to the manufacturer's manual. These libraries were sequenced using the NEXseq500 platform with NextSeq 500/550 High Output Reagent Cartridge v2 (Illumina).

\section{Nanopore sequencing}

Genomic DNA was used to build Nanopore sequencing libraries with Ligation Sequencing Kit (SQK-LSK108, Oxford Nanopore Technologies), following the manufacturer's manual. For the first three runs, genomic DNA was not fragmented, to generate long reads. To obtain more reads, for the fourth run of Nanopore sequencing, genomic DNA was sheared to $8-10$ kilobases by g-TUBE (Covaris, 520079). The libraries were sequenced in R9.4.1 flow cells on a MinION device (Oxford Nanopore Technologies). MinKNOW (v.1.7.3) was used to collect raw signal and Albacore (v.2.3.3) was used for base-calling. All the data were combined for genome assembly.

\section{$\mathrm{Hi}-\mathrm{C}$}

To perform Hi-C on Xenia sp. tissue, we modified a previously published protocol for nuclear in situ ligation ${ }^{13}$, as described in detail.

Fix and dissociate tissues (step 1). Eight polyps (about $10^{8}$ cells) were fixed with $4 \%$ paraformaldehyde (PFA) overnight. After washing twice with $3.3 \times \mathrm{PBS}^{38}$ and dissociating the tissue in $2 \mathrm{ml} 3.3 \times \mathrm{PBS}$ using a $7-\mathrm{ml}$ glass Dounce tissue grinder (Wheaton), another $3 \mathrm{ml} 3.3 \times$ PBS was added. The mixture was then transferred to a $15-\mathrm{ml}$ conical tube and centrifuged at $1,000 \mathrm{~g}$ for $3 \mathrm{~min}$ (Sorvall Lynx 6000 centrifuge, ThermoFisher Scientific). The pellet was washed once with $5 \mathrm{ml} 3.3 \times$ PBS.

Nuclear permeabilization and chromatin digestion (step 2). The pellet from step 1 was resuspended in $10 \mathrm{ml}$ ice-cold $\mathrm{Hi}$-C lysis buffer (10 mM Tris, pH 8.0, $10 \mathrm{mM} \mathrm{NaCl}, 0.2 \% \mathrm{NP}-40,1 \times$ protease inhibitors cocktail (Roche, 04693132001$)$ ) and rotated for 30 min at $4{ }^{\circ} \mathrm{C}$ followed by centrifugation at $1,000 \mathrm{~g}$ for $5 \mathrm{~min}$ at $4{ }^{\circ} \mathrm{C}$. The pellet was resuspended with $1 \mathrm{ml}$ ice-cold $1.2 \times$ NEB3.1 $\left(120 \mu \mathrm{I}\right.$ NEB3.1 to $\left.880 \mu \mathrm{IddH}_{2} \mathrm{O}\right)$ buffer and transferred to a $1.5-\mathrm{ml}$ microcentrifuge tube followed by centrifugation at $1,000 \mathrm{~g}$ for $5 \mathrm{~min}$ at $4{ }^{\circ} \mathrm{C}$. The pellet was washed again with $1 \mathrm{ml}$ ice-cold $1.2 \times$ NEB3.1 followed by centrifugation. After removing the supernatant, $400 \mu \mathrm{l} 1.2 \times$ NEB3.1 buffer and $12 \mu \mathrm{l}$ of $10 \%$ SDS were added to the pellet. $\mathrm{P} 200$ pipette tip was used to thoroughly resuspend and dissociate the pellet. The mixture was then incubated at $65^{\circ} \mathrm{C}$ for $10 \mathrm{~min}$ at $950 \mathrm{rpm}$ in a Thermomixer (Eppendorf). After cooling the mix on ice for $5 \mathrm{~min}, 40 \mu \mathrm{l} 20 \%$ Triton $\mathrm{X}-100$ was added to the mixture to neutralize the SDS. After carefully mixing by pipetting with a $\mathrm{P} 200$ pipette tip and inverting the tube several times, the mixture was then incubated at $37^{\circ} \mathrm{C}$ for $60 \mathrm{~min}$ with rotation $(950 \mathrm{rpm})$ in a Thermomixer. To digest the crosslinked genomic DNA, $30 \mu$ l of $50 \mathrm{U} / \mu \mathrm{l} \mathrm{BgIII} \mathrm{(NEB} \mathrm{R0144M)} \mathrm{was}$ added to the mixture and incubated overnight at $37^{\circ} \mathrm{C}$ with rotation at $950 \mathrm{rpm}$ in a Thermomixer.

Fill in 5' overhang generated by Bgll digestion with biotin (step 3 ). A nucleotide mix containing dATP, dGTP and dTTP was made by adding $1 \mu \mathrm{l}$ each of $100 \mathrm{mM}$ dATP, dGTP and dTTP into $27 \mu \mathrm{ldd} \mathrm{H}_{2} \mathrm{O}$. To the $480.0 \mu \mathrm{l}$ BgllI-digested nuclear preparation from the above step $2,4.5 \mu$ l of the nucleotide mix, $15 \mu \mathrm{l} 1 \mathrm{mM}$ biotin-16-dCTP (Axxora, JBS-NU-809-BIO16) and $10 \mu \mathrm{l} 5 \mathrm{U} / \mu \mathrm{l} \mathrm{Klenow}$ (NEB, M0210L) were added followed by incubation at $37^{\circ} \mathrm{C}$ for $90 \mathrm{~min}$ with intermittent gentle shaking at $700 \mathrm{rpm}$ for $10 \mathrm{~s}$ after every $20 \mathrm{~s}$ using Thermomixer. The tube was also taken out and inverted every 15-20 min. After this incubation, the mixture was kept on ice. 
Proximity ligation (step 4). The mixture from step 3 was transferred to a $50-\mathrm{ml}$ conical tube followed by adding $750 \mu \mathrm{l} 10 \times \mathrm{T} 4$ ligase buffer (NEB B0202S, no PEG), $75 \mu \mathrm{l} 100 \times$ BSA (NEB), 6,140 $\mu$ l water, $25 \mu \mathrm{l}$ $30 \mathrm{U} / \mu \mathrm{l} \mathrm{T} 4 \mathrm{DNA}$ ligase (Thermo Scientific, EL0013), and incubating at $16^{\circ} \mathrm{C}$ overnight.

Reverse crosslink and DNA isolation (step 5). To the reaction mixture from step 4, $25 \mu \mathrm{l}$ of $20 \mathrm{mg} / \mathrm{ml}$ proteinase K (Invitrogen, 25530-049) was added and the mixture was divided equally into $8 \times 1.5-\mathrm{ml}$ microcentrifuge tubes (about $950 \mu \mathrm{l}$ per tube). The tubes were then incubated overnight at $65^{\circ} \mathrm{C}$ with rotation at $950 \mathrm{rpm}$ in a Thermomixer. The next day, $3 \mu \mathrm{l} 20 \mathrm{mg} / \mathrm{ml}$ proteinase $\mathrm{K}$ was added to each tube followed by incubation at $65^{\circ} \mathrm{C}$ for $2 \mathrm{~h}$ with mixing in Thermomixer. The mixtures were combined into one 50-ml conical tube. After cooling down to room temperature, $10 \mathrm{ml}$ phenol ( $\mathrm{pH} \mathrm{8.0)} \mathrm{(Sigma)} \mathrm{was} \mathrm{added} \mathrm{and} \mathrm{mixed} \mathrm{by}$ vortex for $2 \mathrm{~min}$. The mixture was then centrifuged for $10 \mathrm{~min}$ at $3,000 \mathrm{~g}$ (Sorvall Lynx 6000 centrifuge). The supernatant containing the DNA was mixed with $10 \mathrm{ml}$ phenol:chloroform (1:1) (pre-warmed to room temperature) and vortexed for $2 \mathrm{~min}$. The whole mixture was then transferred to a 50-ml MaXtract High Density tube (Qiagen, 129073) and centrifuged at $1,500 \mathrm{~g}$ for $5 \mathrm{~min}$ (Sorvall Lynx 6000 centrifuge). The top phase containing the Hi-CDNA was transferred to a 50-ml conical tube and the volume (usually about $10 \mathrm{ml}$ ) was adjusted to $10 \mathrm{ml}$ with $1 \times$ TE as needed. To pellet the DNA, $1 \mathrm{ml} 3 \mathrm{M} \mathrm{Na}$-acetate, $5 \mu \mathrm{l} 15 \mathrm{mg} / \mathrm{ml}$ GlycoBlue (Invitrogen AM9515) and $10 \mathrm{ml}$ isopropanol were added to the mixture and incubated at $-80^{\circ} \mathrm{C}$ for $>1 \mathrm{~h}$. The DNA was then pelleted by centrifugation at $17,000 \mathrm{~g}$ for $45 \mathrm{~min}$ at $4{ }^{\circ} \mathrm{C}$ (Sorvall Lynx 6000 centrifuge). The $\mathrm{Hi}-\mathrm{C}$ DNA pellet was resuspended in $450 \mu \mathrm{l} 1 \times \mathrm{TE}$ and transferred to a $1.5-\mathrm{ml}$ microcentrifuge tube followed by adding $500 \mu \mathrm{l}$ phenol:chloroform (1:1). After mixing by vortex, the mix was centrifuged at $18,000 \mathrm{~g}$ for $5 \mathrm{~min}$ at room temperature. The top aqueous layer was collected into another tube followed by adding $40 \mu \mathrm{l} 3 \mathrm{M}$ Na-acetate, $1 \mu \mathrm{l} 15 \mathrm{mg} / \mathrm{ml}$ GlycoBlue (Invitrogen AM9515, $300 \mu \mathrm{l}$ ) and $1 \mathrm{ml}$ ice-cold $100 \%$ ethanol. After incubating at $-80^{\circ} \mathrm{C}$ for $>30 \mathrm{~min}$, the DNA was centrifuged at $21,000 \mathrm{~g}$ for $30 \mathrm{~min}$ at $4{ }^{\circ} \mathrm{C}$. The DNA pellet was washed with freshly prepared $70 \%$ ethanol and air-dried, followed by dissolving in $45 \mu \mathrm{l} \mathrm{EB}$ (10mM Tris, $\mathrm{pH}$ 8.0). The contaminated RNA in the DNA preparation was digested by adding $0.5 \mu \mathrm{l} 10 \mathrm{mg} / \mathrm{ml}$ RNaseA and incubated at $37^{\circ} \mathrm{C}$ for $30 \mathrm{~min}$.

Remove biotin from the free DNA (unligated DNA) ends (step 6). To remove the biotin at the free DNA ends, $1.0 \mu \mathrm{l} 10 \mathrm{mg} / \mathrm{ml} \mathrm{BSA} \mathrm{(NEB,}$ $100 \times), 10 \mu \mathrm{l} 10 \times \mathrm{NEB} 2.1$ buffer, $1 \mu \mathrm{l} 10 \mathrm{mM}$ dATP, $1 \mu \mathrm{l} 10 \mathrm{mM}$ dGTP and $5 \mu \mathrm{IT} 4$ DNA polymerase (NEB M0203S), and $42 \mu \mathrm{l}$ water were added to $40 \mu \mathrm{l}$ (about $3 \mu \mathrm{g}$ ) $\mathrm{Hi}-\mathrm{C}$ DNA preparation from step 5 . The mixture was divided into two equal aliquots in 2 PCR tubes and incubated at $20^{\circ} \mathrm{C}$ for $4 \mathrm{~h}$. Then, $2 \mu \mathrm{l}$ of $0.5 \mathrm{M}$ EDTA was added to each of the two tubes to stop the reaction. The Hi-C DNA was then purified using the Clean and Concentrator Kit (ZYMO, D4013) followed by elution with $50 \mu \mathrm{lEB}$.

Biotin pull-down of DNA and second DNA digestion (step 7). In brief, $60 \mu \mathrm{l}$ of Dynabeads MyOne Streptavidin C1 (Invitrogen) was washed in $1.5-\mathrm{ml}$ non-sticking microcentrifuge tubes (Ambion) with $200 \mu \mathrm{l} 2 \times$ binding buffer ( $10 \mathrm{mM}$ Tris, $\mathrm{pH} 8,0,1 \mathrm{mM}$ EDTA, $2 \mathrm{M} \mathrm{NaCl}$ ) twice, followed by resuspension in $50 \mu \mathrm{l} 2 \times$ binding buffer. The $50 \mu \mathrm{l}$ $\mathrm{Hi}-\mathrm{C}$ DNA from step 6 was added followed by rotating for 30 min using Intelli-Mixer (ELMI) at room temperature. The beads were collected using a magnetic stand and washed with $100 \mu \mathrm{l} 1 \times$ binding buffer followed by washing with $100 \mu \mathrm{l} 1 \times$ NEB4 buffer twice and resuspending in $50 \mu \mathrm{l} 1 \times$ NEB4 buffer. The DNA on beads was digested using $1 \mu \mathrm{l}$ $10 \mathrm{U} / \mu \mathrm{l}$ Alul (NEB, R0137S) at $37^{\circ} \mathrm{C}$ for $60 \mathrm{~min}$. The beads were collected on a magnetic stand followed by washing with $100 \mu \mathrm{l} 1 \times$ binding buffer, and then $100 \mu \mathrm{lEB}$. The beads were resuspended in $30 \mu \mathrm{lEB}$.
A-tailing (step 8). The 30- $\mu$ l beads from step 7 were mixed with $5 \mu$ I NEB

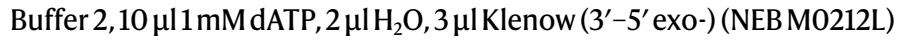
and incubated at $37^{\circ} \mathrm{C}$ for $45 \mathrm{~min}$. After the reaction, the beads were collected by a magnetic stand followed by washing with $100 \mu \mathrm{l} 1 \times$ binding buffer and then $100 \mu \mathrm{lEB}$. The beads were resuspended in $50 \mu \mathrm{lEB}$.

Sequencing adaptor ligation (step 9). The 50- $\mu$ l beads from step 8 was mixed with $3.75 \mu$ l sequencing adaptor (TruSeq RNA Sample Prep Kit v.2), $10 \mu \mathrm{l} 1 \times$ T4 DNA ligase buffer, $3 \mu \mathrm{l} \mathrm{T} 4$ DNA Ligase (30 U/ $\mu \mathrm{l})$ (Thermo Scientific, EL0013) and incubated at room temperature for $2 \mathrm{~h}$. The beads were collected by a magnetic stand followed by washing twice with $400 \mu \mathrm{l} 1 \times$ binding buffer $+0.05 \%$ Tween, $200 \mu \mathrm{l} 1 \times$ binding buffer, and then $100 \mu \mathrm{lEB}$. The beads were resuspended in $40 \mu \mathrm{IEB}$. To release the DNA from the beads, the mixture was incubated at $98^{\circ} \mathrm{C}$ for $10 \mathrm{~min}$ and then centrifuged at $500 \mathrm{rpm}$ to pellet the streptavidin beads.

Sequencing library preparation (step 10). TruSeq RNA Library Prep Kit was used to make DNA sequencing library (eight PCR cycles were used) and the DNA was sequenced by NextSeq 500 .

\section{scRNA-seq}

For each of the six scRNA-seq library preparation, 1 polyp, 8 tentacles, and 2 stalks or 2 regenerating stalks of Xenia sp. were dissociated into single cells in $1 \mathrm{ml}$ digestion buffer, containing $3.6 \mathrm{mg} / \mathrm{ml}$ dispase II (Sigma, D4693), 0.25 mg/ml liberase (Sigma, 5401119001), 4\% $\mathrm{L}$-cysteine in $\mathrm{Ca}^{2+}$-free seawater $(393.1 \mathrm{mM} \mathrm{NaCl}, 10.2 \mathrm{mM} \mathrm{KCl}, 15.7 \mathrm{mM}$ $\mathrm{MgSO}_{4} \cdot 7 \mathrm{H}_{2} \mathrm{O}, 51.4 \mathrm{mM} \mathrm{MgCl}_{2} \cdot 6 \mathrm{H}_{2} \mathrm{O}, 21.1 \mathrm{mM} \mathrm{Na}_{2} \mathrm{SO}_{4}$, and $3 \mathrm{mM} \mathrm{NaHCO}_{3}$, $\mathrm{pH}$ 8.5) and incubated for $1 \mathrm{~h}$ at room temperature. After digestion, fetal bovine serum was added to a final concentration of $8 \%$ to stop enzymatic digestion. The cell suspension was filtered through a $40-\mu \mathrm{m}$ cell strainer (FALCON). A low concentration $(0.1 \mu \mathrm{g} / \mathrm{ml})$ of DAPI that can only be taken up by dead cells was used to measure cell viability. Only cell suspensions in which more than $90 \%$ of cells that did not take up DAPI were used. Cells were counted by haemocytometer and diluted with the same $4 \% \mathrm{~L}$-cysteine in $\mathrm{Ca}^{2+}$-free seawater used in the digestion buffer into 1,000 cells per $\mu$ l. Around 17,000 cells per sample were used for single-cell library preparation using the $10 x$ Genomics platform with Chromium Single Cell 3' Library and Gel Bead Kit v.2 (PN-120267) (v.2 chemistry) or Chromium Next GEM Single Cell 3' GEM, Library and Gel Bead Kit v.3.1 (PN-1000121, v.3 chemistry), Single Cell 3' A Chip Kit (PN1000009) or Chromium Next GEM Chip G Single Cell Kit (PN-1000127), and i7 Multiplex Kit (PN-120262). For the scRNA-seq library construction, we followed the $10 x$ protocol exactly. In brief, for v. 2 chemistry, $17.4 \mu \mathrm{l}$ cell suspension and $16.4 \mu \mathrm{l}$ nuclease-free water were mixed with $66.2 \mu \mathrm{l}$ reverse transcription master mix. Of this $100 \mu \mathrm{l}$ mix, $90 \mu \mathrm{l}$ was loaded into the chip provided in the Single Cell 3' A Chip Kit. For v.3 chemistry, $16.5 \mu \mathrm{l}$ cell suspension and $26.7 \mu \mathrm{l}$ nuclease-free water were mixed with $31.8 \mu \mathrm{l}$ reverse transcription master mix. Of this $75 \mu \mathrm{l}$ mix, $70 \mu \mathrm{l}$ was loaded into the Chromium Next GEM Chip G. After barcoding, cDNA was purified and amplified with 11 PCR cycles. The amplified cDNA was further purified and subjected to fragmentation, end repair, A-tailing, adaptor ligation and 14 cycles of sample index PCR. Libraries were sequenced using Illumina NextSeq 500 for paired-end reads. Read 1 is $26 \mathrm{bp}$ ( $\mathrm{v} .2$ chemistry) or $28 \mathrm{bp}$ ( $\mathrm{v} .3 .1$ chemistry) and read 2 is $98 \mathrm{bp}$.

In our initial scRNA-seq using the $10 x$ Genomics v. 2 chemistry, we obtained fewer unique molecular identifiers (UMIs) (median number, 801) and genes (median number, 467) per Xenia cell compared to other model organisms, such as the mouse thymus ${ }^{39}$ (median UMI 5,802 and median gene number 2,178 ), but higher than in Nematostella ${ }^{18}$ (median UMI 541 and median gene number 278). The new and improved v.3 chemistry substantially improved our scRNA-seq. We captured more cells per library (v.37,874 versus v.22,883), a higher number of median genes per cell, (v.3 943 versus v. 2467 ) and median UMI per cell (v.3 2,027 versus v.2 801). Our v.3 dataset has lower quality than those of 
the mouse thymus ${ }^{39}$ and $H y d r a^{40}$ scRNA-seq datasets (Supplementary Table 1). This suggests that, even using v.3 chemistry, the presence of seawater and/or Xenia-sp.-specific features may contribute to the reduced scRNA-seq quality.

We noticed the mapping rate in v. 3 chemistry is lower than in v. 2 chemistry. We sequenced more reads for the v.3 libraries, because v. 3 captured more total cells and more RNA molecules per cell. Although we sequenced more for the v. 3 libraries, we obtained lower sequence saturation (on average, $79.6 \%$ in v. 3 libraries and $92.6 \%$ in v. 2 libraries). Because the v. 2 and v. 3 reagent contents are proprietary information, it is difficult for us to assess why the two methods gave different results. Regarding our library preparation, the v. 3 method entailed $22 \%$ of the total volume coming from the cell suspension in the $\mathrm{Ca}^{2+}$-free seawater, while in the v. 2 method, $17.4 \%$ of the total volume came from the $\mathrm{Ca}^{2+}$-free seawater cell suspension. We therefore know that one difference between the two methods is that the salt concertation in $\mathrm{v.} 3$ library preparation is higher than that in the v. 2 library preparation. The higher salt concentration in v. 3 could lead to a higher RNA extraction efficiency in the v.3 library preparation, which could contribute to the difference between our v,2-and v,3-based scRNA-seq. Althought the $10 x$ platform worked well for the Xenia sp. we studied here, it is important to keep in mind that modifications may be needed for successful scRNA-seq for other marine cnidarians.

\section{Quantification of endosymbiotic Xenia cells by microscopy and FACS}

To quantify the endosymbiotic cell percentage in Xenia, we first applied a microscopy-based strategy. By imaging cryo-preserved tissue sections stained with $1 \mu \mathrm{g} / \mathrm{ml}$ DAPI that labelled all nuclei, we determined the total number of Xenia cells per section by counting the number of Xenia cell nuclei: these nuclei are easily differentiated from the alga nuclei when overlapped with the autofluorescence signal in far red channel from algae. The number of Xenia cells containing alga is estimated by counting the number of algae surrounded by Xenia tissue. The estimated percentage by this method is on average 2-6\%, depending on whether the sections were taken from stalks or tentacles (Extended Data Fig. 4d). The limitation of this method is that some algae that appear to be inside the tissue may be between Xenia cells and not inside cells. Therefore, this estimate could represent an upper limit of the percentage of alga-containing Xenia cells.

In the second method, we used FACS to separate free algae and algae contained inside the Xenia cells. Xenia polyps were dissociated into single-cell suspension with the same preparation method as described in 'scRNA-seq'. The cells were fixed with $1 \%$ (final concentration) formaldehyde on ice for $1 \mathrm{~h}$, followed by $0.2 \%$ Triton $\mathrm{X}-100$ permeablization and $1 \mu \mathrm{g} / \mathrm{ml}$ DAPI staining. We first separated free algae and alga-containing Xenia cells according to the algae autofluorescence in the Cy5.5 channel. Free algae and algae inside Xenia cells should have different forward scatter (FSC) and side scatter (SSC) signals because the alga inside Xenia cells is enclosed by the Xenia cellular membrane structure. Thus, we used FSC and SSC to further gate the total population of algae into two subpopulations. Microscopy analyses showed that this gating separated free algae and alga-containing Xenia cells. To determine the total Xenia cell number, Xenia cells together with algal cells were gated according to DAPI-positive signal followed by gating with the Cy5.5 signal. The total Xenia cells were calculated as alga-free Xenia cells plus the alga-containing Xenia cells. On the basis of these FACS analyses, we were able to estimate the percentage of alga-containing Xenia cells in Xenia polyps to be about $2 \%$ of total Xenia cells. The illustration of this FACS sorting can be found in Extended Data Fig. 7b-g. Because the procedure of single-cell dissociation may cause an alga-containing Xenia cell to lose its alga, the approximately $2 \%$ of alga-containing Xenia cells obtained by the FACS method probably represents an underestimation. Thus, we estimate the fraction of alga-containing Xenia cells to be about $2-6 \%$.

\section{Bulk RNA-seq}

Total RNA was isolated from 3 polyps, 32 tentacles or 6 stalks by RNeasy Plus Mini Kit (Qiagen). To obtain additional transcriptomes from different cell types, we dissociated coral tissue into individual cells according to a previously published method $^{41}$ and subjected the dissociated cells to OptiPrep-based cell separation ${ }^{42}$. Cells with different densities were separated into four layers, and RNA was isolated from each layer with RNeasy Plus Mini Kit (Qiagen). For transcriptome of FACS-isolated alga-containing and alga-free cells, three polyps were dissociated with the same protocol as used in the scRNA-seq and the dissociated cells were subjected to FACS. Cy5.5-positive and-negative cells were collected as alga-containing and alga-free cells, respectively, and used for total RNA extraction as above. cDNA libraries were built according to TruSeq Stranded mRNA Library Prep Kit (Illumina) and subjected to Illumina NextSeq 500 for sequencing. For gene annotation, paired-end sequencing of $75 \mathrm{bp}$ for each end was used. For FACS-isolated bulk-cell transcriptomes, single-end sequencing of $75 \mathrm{bp}$ was used.

\section{Xenia regeneration, BrdU labelling and EdU pulse-chase}

Individual Xenia sp. polyps were placed into a well of 24-well cell-culture plate (Corning) containing $1 \mathrm{ml}$ artificial seawater from our aquatic tank. The polyps were allowed to settle in the well for 5-7 days before cutting away the tentacles. After cutting, there were a lot algae released into the seawater, which together with the free algae living inside the cavity of the coral could serve as alga reservoirs for the uptake of algae during regeneration.

For the BrdU labelling experiments, $0.5 \mathrm{mg} / \mathrm{ml} \mathrm{BrdU}$ was added into the well $2 \mathrm{~d}$ before sample collection. The BrdU-labelled stalks were fixed by $4 \%$ PFA overnight, followed by washing with PBST (PBS+0.1\% Tween 20) twice for 10 min each. The stalk was then balanced with $30 \%$ sucrose overnight followed by embedding in OCT, frozen in dry ice bathed in ethanol and subjected to cryo-sectioning. The slides were washed with PBS 3 times for 5 min each time followed by treating with $2 \mathrm{M} \mathrm{HCl}$ containing $0.5 \%$ Triton $\mathrm{X}-100$ for $30 \mathrm{~min}$ at room temperature. The slides were then incubated with PBST (0.2\% Triton X-100 in PBS) 5 min for 3 times each followed by blocking with $10 \%$ goat serum and then incubating with mouse anti-BrdU antibody (ZYMED, 18-0103,1:200 dilution in $10 \%$ goat serum) at $4{ }^{\circ} \mathrm{C}$ overnight. Slides were washed with PBST 3 times for 10 min each followed by incubation with the secondary antibody (Invitrogen) for $1 \mathrm{~h}$ at room temperature and washing with PBST 3 times for 10 min each. The nuclei were counterstained with Hoechst 33342 and the signal was visualized using a confocal microscope (Leica). Clear BrdU signal in the nucleus labelled by Hoechst was counted as a BrdU ${ }^{+}$cell. If the Xenia $\mathrm{BrdU}^{+}$nucleus was juxtaposed to an alga, it was counted as an alga-containing $\mathrm{BrdU}^{+} X e n i a$ cell.

For EdU pulse-chasing experiments, the regenerating Xenia stalks were incubated with $1 \mathrm{mM}$ EdU during regeneration day 3 and day 4 . After washing out EdU, the coral was incubated with artificial seawater and samples were collected on regenerating days $7,9,11,13,15,17$ and 19. The samples were dissociated into single-cell suspensions followed by fixing with $1 \%$ formaldehyde at $4{ }^{\circ} \mathrm{C}$ overnight as described in 'scRNA-seq'. The fixed cells were pelleted at $800 \mathrm{~g}$ for $5 \mathrm{~min}$ and further fixed with 4\% PFA for two days to block the autofluorescence in the 488-nm channel. Then, the EdU click chemistry was carried out using the Click-iT EdU Cell Proliferation Kit (Invitrogen, C10337) according to manufacturer's protocol. The cells were further stained with DAPI, and then analysed by FACS as described in Extended Data Fig. 7 and 'Quantification of endosymbiotic Xenia cells by microscopy and FACS'.

\section{Whole-mount RNA ISH}

To perform RNA ISH on Xenia, we modified the whole-mount RNA ISH protocol for zebrafish ${ }^{43}$.

For making gene-specific sense or anti-sense probes, we designed primers (Supplementary Table 7) to genes of interest for PCR to amplify 
gene fragments from Xenia sp. cDNA. The T3 promoter sequence was added to the $5^{\prime}$ of the reverse primers so that the PCR products could be directly used for synthesizing anti-sense RNA probes by T3 RNA polymerase (Promega, P2083) using DIG RNA Labelling Mix (Roche, 11277073910). DIG-labelled RNA probes were purified by RNA Clean and Concentrator-5 (ZYMO), heated to $80^{\circ} \mathrm{C}$ for $10 \mathrm{~min}$, immediately transferred on ice for $1 \mathrm{~min}$, and then diluted in Prehyb ${ }^{+}$buffer ( $50 \%$ formamide, $5 \times$ saline-sodium citrate buffer (SSC, $0.75 \mathrm{M} \mathrm{NaCl}$, $0.075 \mathrm{M}$ sodium citrate), $50 \mu \mathrm{g} / \mathrm{ml}$ heparin, $2.5 \%$ Tween $20,50 \mu \mathrm{g}$ / $\mathrm{ml}$ single-stranded DNA (Sigma, D1626)) to a final concentration of $0.5 \mu \mathrm{g} / \mathrm{ml}$, and stored at $-20^{\circ} \mathrm{C}$ until use.

Xenia polyps were relaxed in $\mathrm{Ca}^{2+}$-free seawater for 30 min and then fixed in $4 \% \mathrm{PFA}$ in $\mathrm{Ca}^{2+}$-free seawater overnight at $4{ }^{\circ} \mathrm{C}$. Fixed polyps were washed with PBST (0.1\% Tween 20 in PBS) twice for $10 \mathrm{~min}$ each, and then incubated in $100 \%$ methanol at $-20{ }^{\circ} \mathrm{C}$ overnight.The next day, the tissues were washed sequentially in $75 \%, 50 \%$ and $25 \%$ methanol for $5 \mathrm{~min}$ each and then washed in PBST for $10 \mathrm{~min}$. They were then treated with $50 \mu \mathrm{g} / \mathrm{ml}$ proteinase $\mathrm{K}$ in PBST for $20 \mathrm{~min}$ followed by a brief wash in PBST. The tissues were post-fixed in 4\% PFA at room temperature for $20 \mathrm{~min}$ and then washed with PBST 2 times for 10 min each. Prehybridization was performed in Prehyb ${ }^{+}$at $68^{\circ} \mathrm{C}$ for $2 \mathrm{~h}$, followed by incubation with probes in Prehyb ${ }^{+}$overnight at $68^{\circ} \mathrm{C}$. To probe gastrodermis markers, $2 \% \mathrm{SDS}$ (final concentration) was added to help the probes to penetrate the tissue. After probes were removed, samples were washed sequentially in $2 \times \operatorname{SSC}(0.3 \mathrm{M}$ $\mathrm{NaCl}$ and $0.03 \mathrm{M}$ sodium citrate) containing $50 \%$ formamide for 20 min twice, $2 \times$ SSC containing $25 \%$ formamide for $20 \mathrm{~min}, 2 \times \mathrm{SSC}$ for $20 \mathrm{~min}$ twice, and $0.2 \times \mathrm{SSC}$ for $30 \mathrm{~min} 3$ times each, all at $68^{\circ} \mathrm{C}$. Then, samples were washed in PBST at room temperature for 10 min and incubated in DIG blocking buffer (1\% ISH blocking reagent (Roche, 11096176001) in maleic acid buffer (0.1 M maleic acid, $0.15 \mathrm{M}$ $\mathrm{NaCl}, \mathrm{pH} 7.5$ ) for $1 \mathrm{~h}$ at room temperature, followed by incubation in anti-DIG antibody (anti-digoxigenin-AP (Roche, 11093274910)) at $1: 5,000$ dilution in DIG blocking buffer overnight at $4{ }^{\circ} \mathrm{C}$. The next day, the samples were washed in PBST for $10 \mathrm{~min} 3$ times each at room temperature, then in 9.5T buffer $(100 \mathrm{mM}$ Tris $-\mathrm{HCl} \mathrm{pH} \mathrm{9.5,50} \mathrm{mM}$ $\mathrm{MgCl}_{2}, 100 \mathrm{mM} \mathrm{NaCl}, 0.1 \%$ Tween 20) for $10 \mathrm{~min} 3$ times each at room temperature. Hybridization signals were revealed by incubation in BCIP/NBT buffer (1 SIGMAFAST BCIP/NBT tablet (Sigma, B5655) in $\left.10 \mathrm{ml} \mathrm{H}_{2} \mathrm{O}\right)$ ) at $4{ }^{\circ} \mathrm{C}$ until brown-purplish colours were sufficiently dark. For this study, the colour development took $48 \mathrm{~h}$. The samples were then washed in PBST twice for 10 min each. The samples were post-fixed in $4 \%$ PFA overnight at $4{ }^{\circ} \mathrm{C}$, followed by washing in PBST twice for $10 \mathrm{~min}$ each, and then washed in methanol for $3 \mathrm{~h}$ at room temperature. The tissues were kept in PBS and imaged using SMZ1500 microscope (Nikon) under Ring Light System (Fibre-Lite). For cross-sections of stalks, the whole-mount sample was processed for cryo-section as described in 'Xenia regeneration, BrdU labelling and EdU pulse-chase'.

\section{RNAscope ISH assay for LePin and Granulin 1 expression}

To visualize RNA expression in endosymbiotic cells, we used the ultrasensitive RNAscope ISH approach (Advanced Cell Diagnostics (ACD)). LePin- or Granulin-1-specific oligonucleotide probes were ordered from ACD (see Supplementary Table 7 for further information). The fluorescent RNAscope assay was carried out by RNAscope Multiplex Fluorescent Reagent Kit v.2 (ACD) according to the manufacturer's protocol. The chromogenic assay was carried out by RNAscope $2.5 \mathrm{HD}$ Duplex Detection Kit (ACD), according to manufacturer's protocol. Both assays used the cryo-section of the fixed Xenia polyp prepared according to the manufacturer's protocol.

\section{Genome assembly}

Sequencing data from Nanopore were used to initiate the genome assemble by Canu (v.1.7) ${ }^{44}$. The assembled genome was further polished with Illumina short reads by Nanopolish (v.0.9.2, https:// github.com/jts/nanopolish) with 5 cycles, which resulted in 1,482 high-quality contigs for the diploid genome. The diploid genome assembly was separated into haploid by HaploMerger $2^{45}$. The haploid genome assembly was further subject to $\mathrm{Hi}-\mathrm{C}$ assisted scaffolds by $3 \mathrm{D}$ de novo assembly pipeline, Juicer (v.1.5) ${ }^{14}$. By aligning all the Illumina genomic sequencing data with the assembled genome, we found $0.45 \%$ single nucleotide polymorphism (SNP) within the whole assembled genome of the Xeniasp.

\section{Gene annotation}

The funannotate genome annotation pipeline (v.1.3.3, https://github. com/nextgenusfs/funannotate) was used to annotate the Xenia sp. genome. In brief, transcriptome data were assembled by Trinity (v.2.6.6 ${ }^{46}$ and used to generate the gene models based on the presence of mRNA by PASApipeline (v.2.3.2) ${ }^{47}$. These gene models were used as training sets to perform de novo gene prediction by AUGUSTUS $(v .3 .2 .3)^{48}$ and GeneMark-ES Suite (v.4.32) ${ }^{49}$. All gene models predicted by PASApipeline, AUGUSTUS and GeneMark were combined and subjected to EVidenceModeller to generate combined gene models ${ }^{50}$. The predicted genes were filtered out if more than $90 \%$ of the sequence overlapped with repeat elements as identified by RepeatMasker and RepeatModeler (http://www.repeatmasker.org). PASA was further used to add $3^{\prime}$ and $5^{\prime}$ untranslated region sequences to the remaining predicted genes. Pfam (v.31.0), Interpro (v.67.0), Uniprot (v.2018_03), BUSCO (v.1.0) $)^{51}$ databases and eggnog-mapper (v.1.3) ${ }^{52}$ were used to annotate the function of these gene models. Among all the predicted genes, 23,939 (82.5\%) gene models were supported by transcriptome data because they have detectable reads (reads number $>0$ ). Among these models, 20,397 have read numbers $>5$.

\section{Phylogeny tree analysis}

We used OrthoFinder (v.2.2.7) to find orthologues from different species on the basis of protein sequences from 13 species listed Fig. 1d, and inferred the species tree $\mathrm{e}^{53,54}$. In brief, 'orthofinder -S diamond - $t 22$-M msa - $f$ fasta_files' was used to generate the result. Diamond (v.0.9.21) was used for sequence search and OrthoFinder grouped 308,348 genes ( $83.8 \%$ of total) into 19,244 orthogroups. One thousand six hundred and one orthogroups, according to previously reported method $^{55}$, with a minimum 10 species having single-copy genes, were used to infer the species tree. These orthogroups were subjected to multiple sequence alignment by MAFFT (v.7.407) and columns with more than eight gaps were trimmed. The trimmed alignment with 73.6\% data occupancy (see Source Data for Fig. 1d) was used to infer the maximum likelihood unrooted species tree by FastTree (v.2.1.10) with the default configuration in OrthoFinder. This species tree was further rooted by the STRIDE algorithm, which has been demonstrated to correctly root the species tree spanning a wide range of time scales and taxonomic groups ${ }^{56}$.

\section{Single-cell clustering and marker gene identification}

The raw single-cell sequencing data were de-multiplexed and converted to FASTAQ format by Illumina bcl2fastaq (v.2.20.0) software. Cell Ranger (v.3.1.0, https://support.10xgenomics.com/ single-cell-gene-expression/software/overview/welcome) was used to de-multiplex samples, process barcodes and count gene expression. The sequence was aligned to the annotated Xenia sp. genome and only the confidently mapped and non-PCR duplicated reads were used to generate gene expression matrix for each library with 'cellranger count' command. The expression matrix of Cell-Ranger-identified cells from each library was read into $\mathrm{R}$ and further analysed with Seurat (v.3.0.2) ${ }^{57}$. Cells with UMI numbers less than 400 or mitochondria gene expression $>0.2 \%$ of total reads were excluded for downstream analysis. To further remove outliers, we calculated the UMI number distribution detected per cell and removed cells in the top $1 \%$ quantile. 
To remove batch effect and integrate data from different libraries, we applied the Seurat v. 3 method for data integration ${ }^{57}$. For each dataset, we identified the top 1,000 genes with the highest dispersion. We used the top 1,000 genes in the non-regeneration sample as anchor features to identify anchors between different non-regeneration datasets. The first 20 dimensions were used to generate the integrated data. Dimensional reduction was carried out on the integrated data, and used for further clustering analysis. Clustering and marker gene identification in non-regeneration condition was further performed with Seurat v.3. The cell clusters in regeneration samples were identified with the label transfer method in Seurat v.3. All violin plots were generated using Seurat VlnPlot function.

\section{Identification of Xenia sp. cells performing endosymbiosis with Symbiodiniaceae}

The bulk transcriptome data of FACS-isolated alga-containing or alga-free Xenia cells were aligned to Xenia sp. genome by STAR $(v .2 .5 .3 a)^{58}$. Individual gene expression (reads per kilobase of transcript, per million mapped reads) for each sample were calculated by RSEM (v.1.3.0) $)^{59}$. The gene-expression levels of each bulk RNA-seq of FACS-isolated cells were compared with the gene-expression levels calculated using average UMI number for each gene in each cell cluster identified by scRNA-seq. The Pearson correlation coefficient was calculated for each comparison.

\section{Pseudotime analysis}

To infer the trajectory of endosymbiotic Xenia cells, we integrated scRNA-seq data of regenerating and non-regenerating samples using Seurat v.3. All cells belonging to the endosymbiotic cell cluster (cluster 16 , total of 382 cells) were subjected to Monocle (v.2.10.1 ${ }^{29}$ analyses. To find the variable genes among these cells for downstream analysis, we grouped these cells into three subclusters with Monocle clusterCells function (with default setting for most parameters, except for num_clusters $=4$, which generated 3 clusters). Each of these three subclusters contains 247,53 or 82 cells. The top 1,000 differentially expressed genes between these three subclusters were used as ordering genes to construct the trajectory by DDRTree algorithm. The differentially expressed genes along pseudotime were detected using the differentialGeneTest function in Monocle. The cell numbers in each of the five predicted endosymbiotic cell states are state $1=36$, state $2=109$, state $3=155$, state $4=45$ and state $5=37$.

\section{RNA velocity}

RNA velocity estimation was carried out using the velocyto.R program (http://velocyto.org, v.0.6), according to the instructions ${ }^{30}$. In brief, velocyto used raw data of the regeneration sample to count the spliced (mRNA) and unspliced intron reads for each gene to generate a loom file. This .loom file was loaded into $\mathrm{R}$ (v.3.6.1) using the read.loom. matrices function and used to generate the RNA velocity map. The RNA velocity map was projected into the $t$-SNE space that was identified by Seurat.

\section{Reporting summary}

Further information on research design is available in the Nature Research Reporting Summary linked to this paper.

\section{Data availability}

We have uploaded all raw genomic, bulk RNA-seq and scRNA-seq data to NCBI (BioProject PRJNA548325). The genome files are available at http://cmo.carnegiescience.edu/data; we have also made the genome data interactive using UCSC genome browser, http://genome.ucsc. edu/cgi-bin/hgTracks?hubUrl=http://cmo.carnegiescience.edu/gb/ hub.txt\&genome=xenSp1. We allow anyone interested to explore the predicted proteomes of Xenia and 14 other cnidarian using our blast server: http://c-moor.carnegiescience.edu:4567. All scRNA-seq analyses and results are available at GitHub: https://github.com/ciwemb/ endosymbiosis. Select intermediate RDS objects are available at: http:// cmo.carnegiescience.edu/data. We have worked to prototype a web portal to organize all the above links. This work-in-progress has a goal of making research findings, experimental protocols and computational data available to the scientific community. As the portal involves information beyond this study, we are still working with colleagues to best design it so that it will be easy to use and informative. The portal can be accessed at: http://cmo.carnegiescience.edu. Source Data are provided with this paper.

\section{Code availability}

R Markdown codes are available at https://github.com/ciwemb/endosymbiosis. For convenience, processed data and code can be downloaded with the following Unix commands: git clone https://github. com/ciwemb/endosymbiosis; wget $-\mathrm{r}-\mathrm{np}$-nH --reject = "index.html*" http://cmo.carnegiescience.edu/endosymbiosis.

36. Hume, B. C. C. et al. An improved primer set and amplification protocol with increased specificity and sensitivity targeting the Symbiodinium ITS2 region. PeerJ 6, e4816 (2018).

37. Urban, J. M., Bliss, J., Lawrence, C. E. \& Gerbi, S. A. Sequencing ultra-long DNA molecules with the Oxford Nanopore MinION. Preprint at https://www.biorxiv.org/ content/10.1101/019281v3 (2015).

38. Rosental, B., Kozhekbaeva, Z., Fernhoff, N., Tsai, J. M. \& Traylor-Knowles, N. Coral cell separation and isolation by fluorescence-activated cell sorting (FACS). BMC Cell Biol. 18 30 (2017).

39. Yue, S., Zheng, X. \& Zheng, Y. Cell-type-specific role of lamin-B1 in thymus development and its inflammation-driven reduction in thymus aging. Aging Cell 18, e12952 (2019).

40. Siebert, S. et al. Stem cell differentiation trajectories in Hydra resolved at single-cell resolution. Science 365, eaav9314 (2019).

41. Helman, Y. et al. Extracellular matrix production and calcium carbonate precipitation by coral cells in vitro. Proc. Natl Acad. Sci. USA 105, 54-58 (2008).

42. Mass, T. et al. Cloning and characterization of four novel coral acid-rich proteins that precipitate carbonates in vitro. Curr. Biol. 23, 1126-1131 (2013).

43. Hu, M. et al. Liver-enriched gene 1, a glycosylated secretory protein, binds to FGFR and mediates an anti-stress pathway to protect liver development in zebrafish. PLoS Genet. 12, e1005881 (2016).

44. Koren, S. et al. Canu: scalable and accurate long-read assembly via adaptive k-mer weighting and repeat separation. Genome Res. 27, 722-736 (2017).

45. Huang, S. et al. HaploMerger: reconstructing allelic relationships for polymorphic diploid genome assemblies. Genome Res. 22, 1581-1588 (2012)

46. Grabherr, M. G. et al. Full-length transcriptome assembly from RNA-seq data without a reference genome. Nat. Biotechnol. 29, 644-652 (2011).

47. Haas, B. J. et al. Improving the Arabidopsis genome annotation using maximal transcript alignment assemblies. Nucleic Acids Res. 31, 5654-5666 (2003).

48. Stanke, M. \& Morgenstern, B. AUGUSTUS: a web server for gene prediction in eukaryotes that allows user-defined constraints. Nucleic Acids Res. 33, W465-W467 (2005).

49. Ter-Hovhannisyan, V., Lomsadze, A., Chernoff, Y. O. \& Borodovsky, M. Gene prediction in novel fungal genomes using an ab initio algorithm with unsupervised training. Genome Res. 18, 1979-1990 (2008).

50. Haas, B. J. et al. Automated eukaryotic gene structure annotation using EVidenceModeler and the program to assemble spliced alignments. Genome Biol. 9, R7 (2008).

51. Simão, F. A., Waterhouse, R. M., loannidis, P., Kriventseva, E. V. \& Zdobnov, E. M. BUSCO: assessing genome assembly and annotation completeness with single-copy orthologs. Bioinformatics 31, 3210-3212 (2015).

52. Huerta-Cepas, J. et al. Fast genome-wide functional annotation through orthology assignment by eggNOG-Mapper. Mol. Biol. Evol. 34, 2115-2122 (2017).

53. Emms, D. M. \& Kelly, S. OrthoFinder: solving fundamental biases in whole genome comparisons dramatically improves orthogroup inference accuracy. Genome Biol. 16, 157 (2015).

54. Emms, D. M. \& Kelly, S. OrthoFinder: phylogenetic orthology inference for comparative genomics. Genome Biol. 20, 238 (2019).

55. Emms, D. M. \& Kelly, S. STAG: species tree inference from all genes. Preprint at https:// www.biorxiv.org/content/10.1101/267914v1 (2018).

56. Emms, D. M. \& Kelly, S. STRIDE: species tree root inference from gene duplication events. Mol. Biol. Evol. 34, 3267-3278 (2017).

57. Stuart, T. et al. Comprehensive integration of single-cell data. Cell 177, 1888-1902 (2019).

58. Dobin, A. et al. STAR: ultrafast universal RNA-seq aligner. Bioinformatics 29, 15-21 (2013).

59. Li, B. \& Dewey, C. N. RSEM: accurate transcript quantification from RNA-seq data with or without a reference genome. BMC Bioinformatics 12, 323 (2011).

Acknowledgements We thank F. Tan and A. Pinder for assistance with all the sequencing; F. Tan and Q. Zhang for assistance in establishing the Carnegie Coral and Marine Organisms web portal and GitHub; Y. Bai for assistance with cell sorting; M. Sepanski for assistance with electron microscopy; N. Marvi for the coral sketch; and L. Hugendubler and M. Watts for maintaining the coral aquarium. This work was supported by Gordon and Betty Moore 


\section{Article}

Foundation, Aquatic Symbiosis no. GBMF9198 (https://doi.org/10.37807/GBMF9198, Y.Z.)

NIH/NIGMS GM106023 (YZ), GM110151 (YZ) NIH/NIAMS AR060042 (C.-M.F) and AR071976

(C.-M.F.).

Author contributions C.-M.F. and Y.Z. conceived and supervised the project. M.H., C.-M.F. and Y.Z. designed experiments. M.H. performed the experiments. M.H. and X.Z. analysed the data

M.H., X.Z., C.-M.F. and X.Z. interpreted the data and wrote the manuscript.

Competing interests The authors declare no competing interests.
Additional information

Supplementary information is available for this paper at https://doi.org/10.1038/s41586-020-

2385-7.

Correspondence and requests for materials should be addressed to M.H., C.-M.F. or Y.Z

Peer review information Nature thanks Mónica Medina Munoz and the other, anonymous, reviewer(s) for their contribution to the peer review of this work. Peer reviewer reports are available.

Reprints and permissions information is available at http://www.nature.com/reprints. 


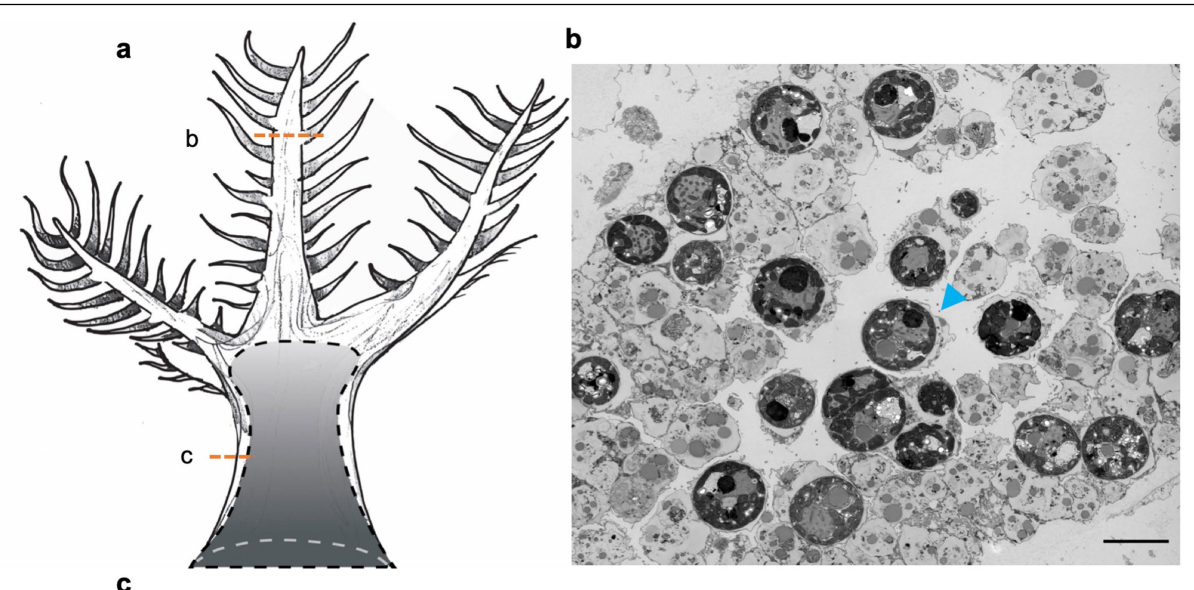

c

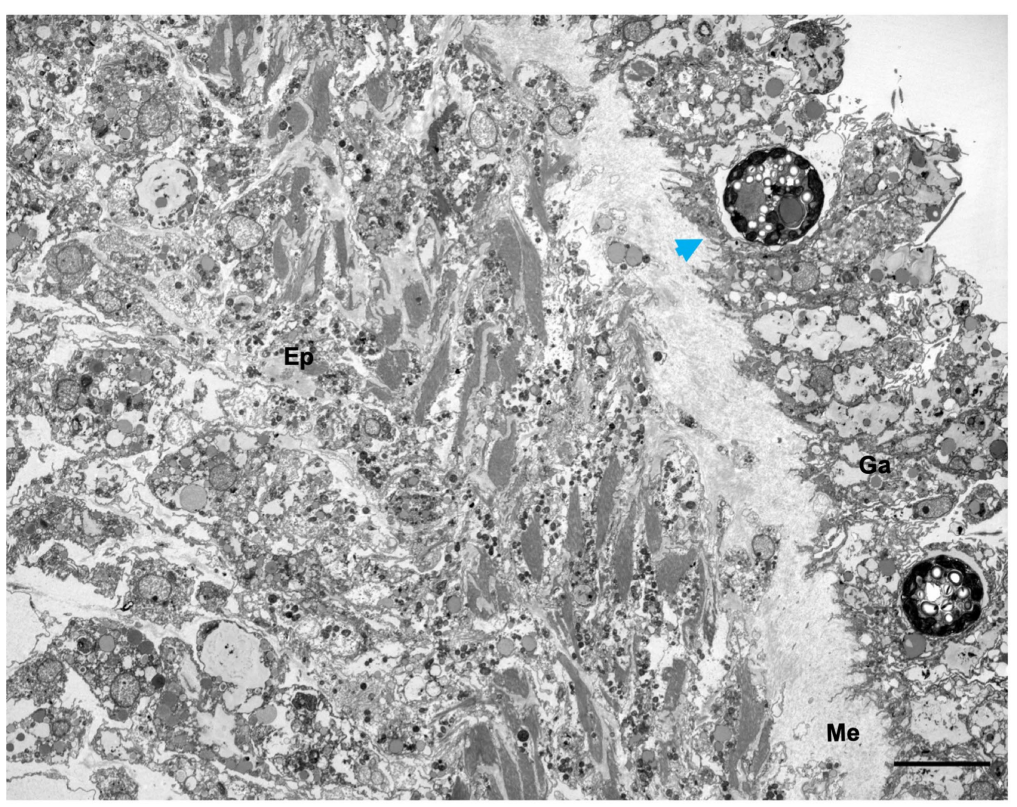

Extended Data Fig. 1 | Electron microscopy analysis of Xenia sp.

a, Illustration of a Xenia polyp. The orange dashed lines indicate where the electron microscopy images were taken, shown in $\mathbf{b}$ and $\mathbf{c} . \mathbf{b}, \mathbf{c}$, Electron microscopy images. Ep, epidermis; Ga, gastrodermis; Me, mesoglea. Blue arrowheads, alga-containing Xenia cells. Five independent polyps from two independent experiments were used for electron microscopy. Scale bars, $10 \mu \mathrm{m}$. 


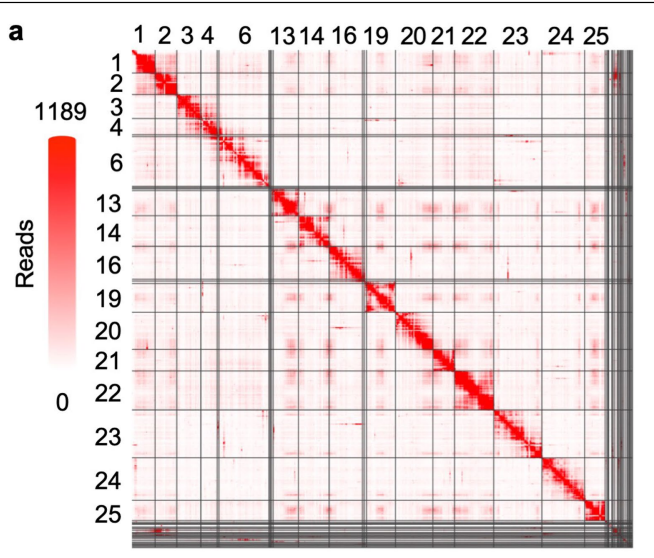

$\mathrm{Hi}-\mathrm{C}$ based genome scaffolds

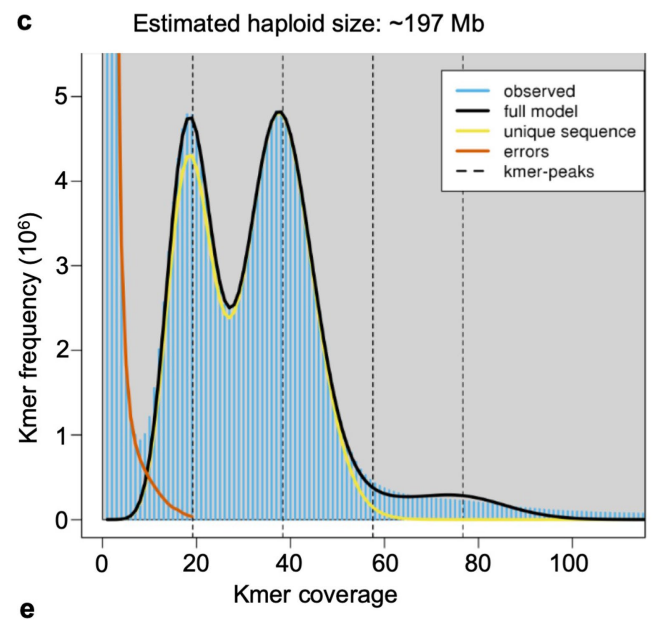

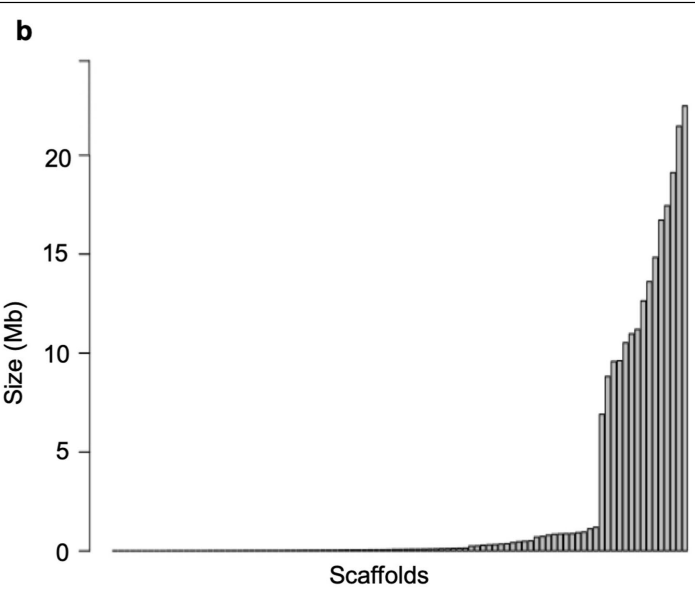

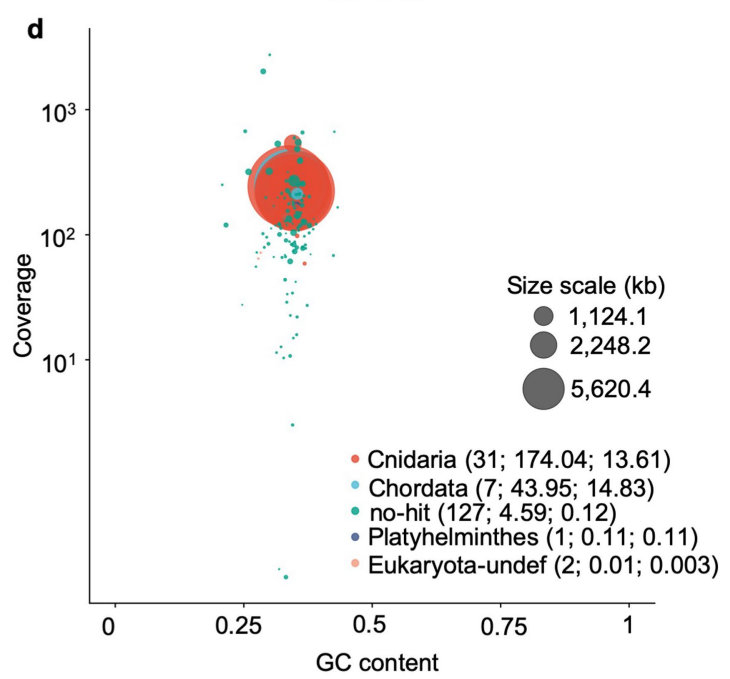

Parameters

Values

\begin{tabular}{ll}
\hline Genome size, predicted by GenomeScope & $197 \mathrm{Mb}$ \\
\hline Total size of genome assembly, in 168 scaffolds & $222,699,500 \mathrm{bp}$ \\
\hline Total contig size, in 556 contigs & $222,505,550 \mathrm{bp}$ \\
\hline Scaffold N50 & $14,832,246 \mathrm{bp}$ \\
\hline Longest scaffold & $22,481,500 \mathrm{bp}$ \\
\hline Contig N50 & $1,122,448$ bp \\
\hline Longest contig & $4,187,899$ bp \\
\hline Number of gene models & 29015 \\
\hline Number of protein coding genes & 28011 \\
\hline Number of apparently complete gene models* & 27640 \\
\hline Number of predicted proteins with recognizable (E-value $\leq 1 \mathrm{e}-5)$ similarity in ncbi nr database & 21783 \\
\hline Mean predicted protein length & 414 amino acid \\
\hline Repeat content & $46.22 \%$ \\
\hline
\end{tabular}

Extended Data Fig. 2 | Additional genome assembly data.a, Hi-C-based Xenia sp. genome assembly. The scaffolds are separated by grids demarcated by black lines. The numbers for the 15 longest scaffolds out of the total 168 scaffolds are shown. b, Size distribution of Xenia sp. genome scaffolds. Each bar on the $x$ axis represents a scaffold. $c$, Xenia sp. genome is predicted to be diploid, as expected, with a haploid genome size of about $197 \mathrm{Mb}$, on the basis of GenomeScope analysis of Illumina short reads. d, Contamination analysis by BlobTools revealed a similar GC content and genomic coverage across most scaffolds. Each coloured circle in the graph represents a scaffold.
Larger circles have longer scaffold lengths; the three grey circles provide the length scale used in the plot. The colour codes represent the closest species group that has the highest sequence similarities to the Xenia sp. scaffolds (the first number in each set of parentheses shows the Xenia scaffold number followed by the combined length of the scaffolds and scaffold N50 value (minimum contig length needed to cover $50 \%$ of the combined scaffold length) in $\mathrm{Mb}$ ). e, A summary of Xenia sp. genome assembly and gene annotation. ${ }^{*}$ Genes encoding protein sequences with apparent in frame start and stop codons. 


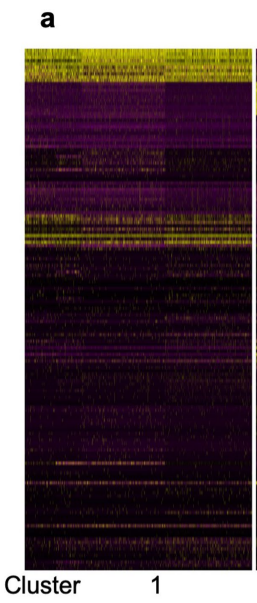

b

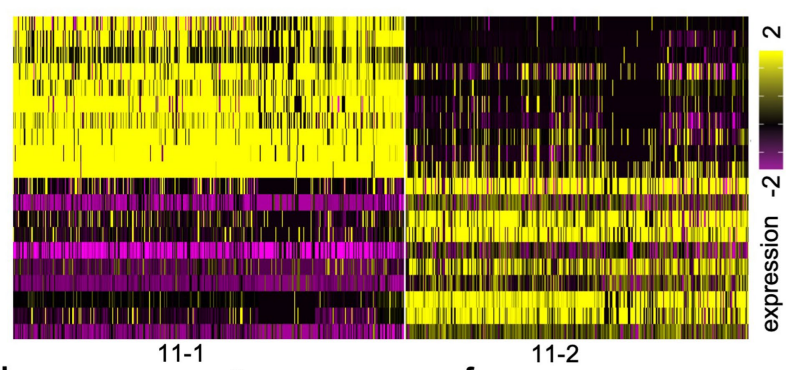

d Minicollagen1 e Nematogalectin2 $\mathbf{f}$

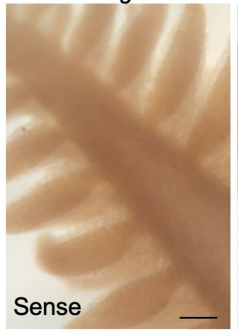

h

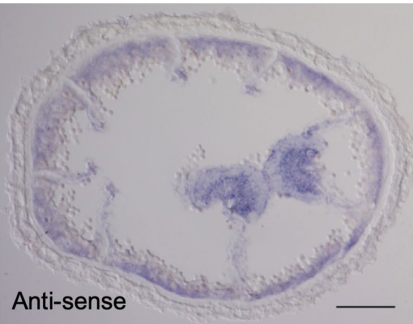

$X e \_003623$

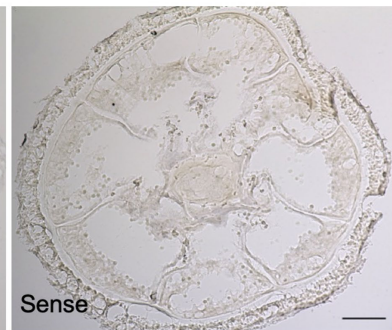

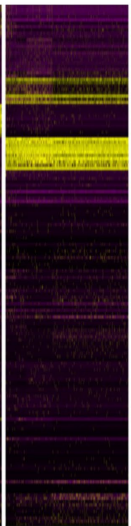

5

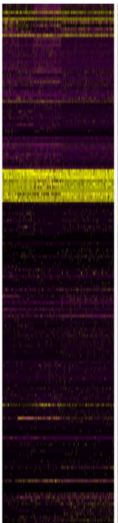

6

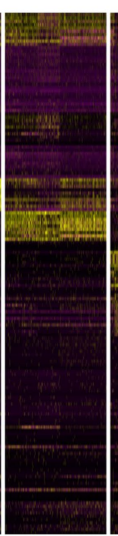

7

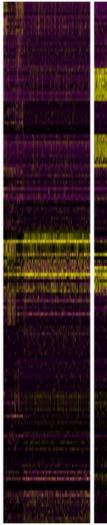

8 expression

$0 \square+2$

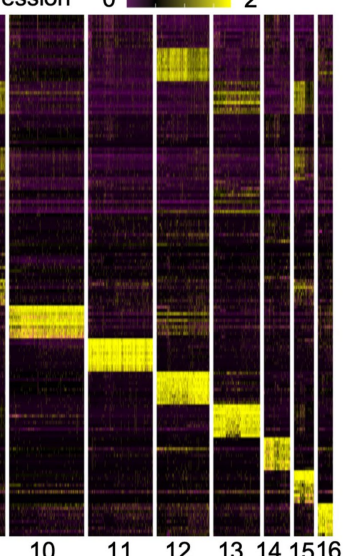

C

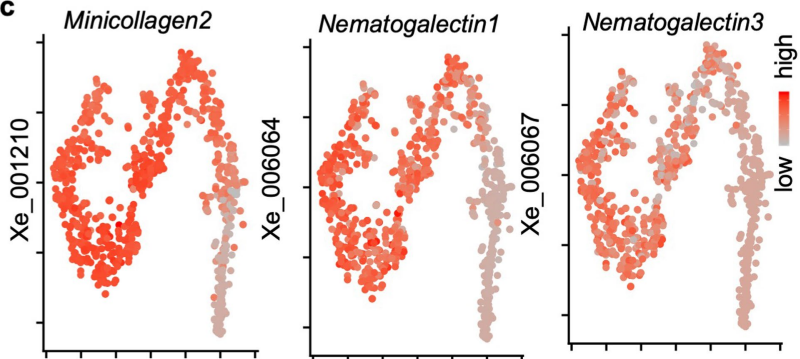

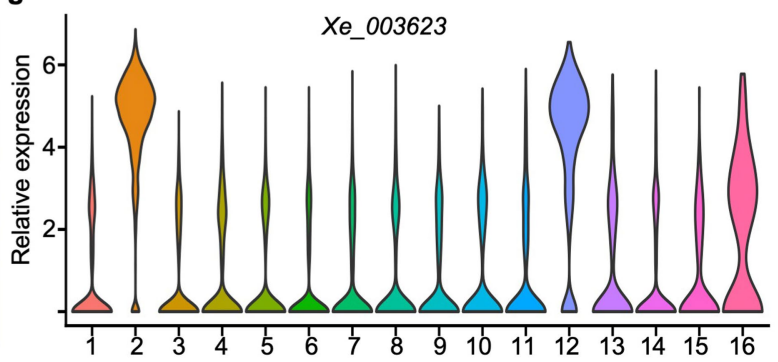

i

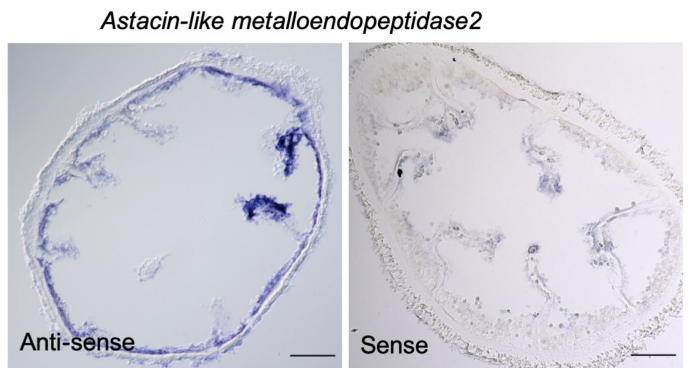

Extended Data Fig. 3 | Additional scRNA-seq analyses. a, Heat map showing differential gene expression patterns of all cells in the 16 assigned cell clusters (indicated at the bottom). Each column is one cell cluster, and each row represents one gene. b, Heat map showing differential gene expression patterns of two subclusters in cluster 11 (11-1 and 11-2). c, Expression levels (as in the coloured expression scale) of 3 cluster-11 markers, Minicollagen 2, Nematogalectin 1 and Nematogalectin 3 , are shown in the $t$-SNE plots. $n=797$ cells. $\mathbf{d}-\mathbf{f}$, RNA ISH control with sense probe for Minicollagen $1(\mathbf{d})$, Nematogalectin 2 (e) and Collagen $6(\mathbf{f})$. g, Expression levels of Xe_003623, a non-conserved and uncharacterized cluster- 2 and -12 marker gene, in each of the 16 cell types defined by scRNA-seq. Violin plot (Methods) show the distribution of gene expression in each of the 16 clusters. Cell numbers in cell clusters $1-16$ were 2,$794 ; 2,704 ; 2,073 ; 1,679 ; 1,511 ; 1,374 ; 1,248 ; 1,069 ; 986 ; 923$; $797 ; 649 ; 575 ; 321 ; 246$; and 185 , respectively. h, i, RNA ISH of $X e_{-} 003623(\mathbf{h})$ and Astacin-like metalloendopeptidase 2 (i) using anti-sense and sense probes. In $\mathbf{d}-\mathbf{f}, \mathbf{h}, \mathbf{i}$, more than 12 polyps from 3 independent experiments were used for each probe. Scale bars, $100 \mu \mathrm{m}$. 

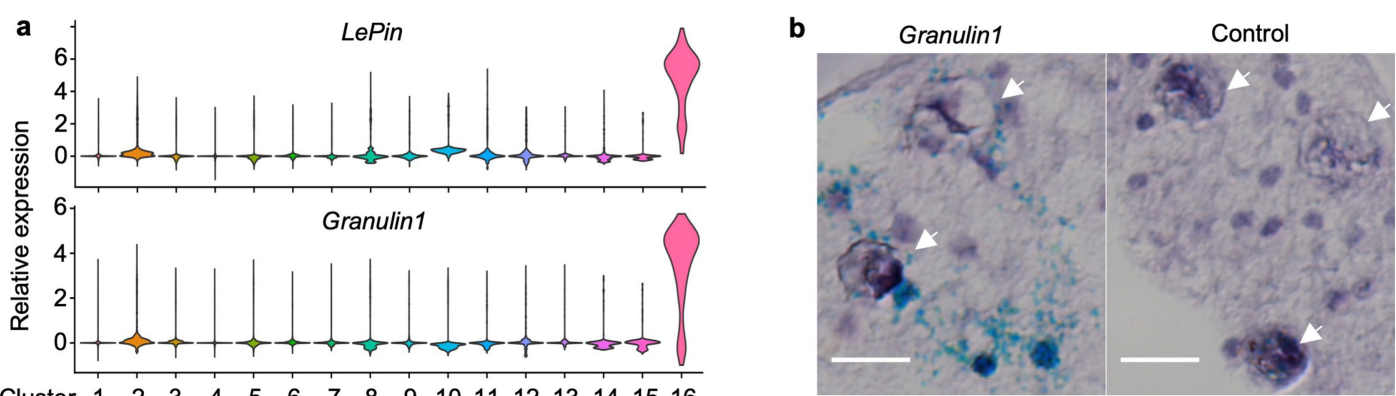

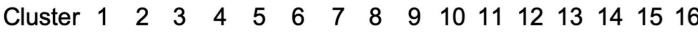

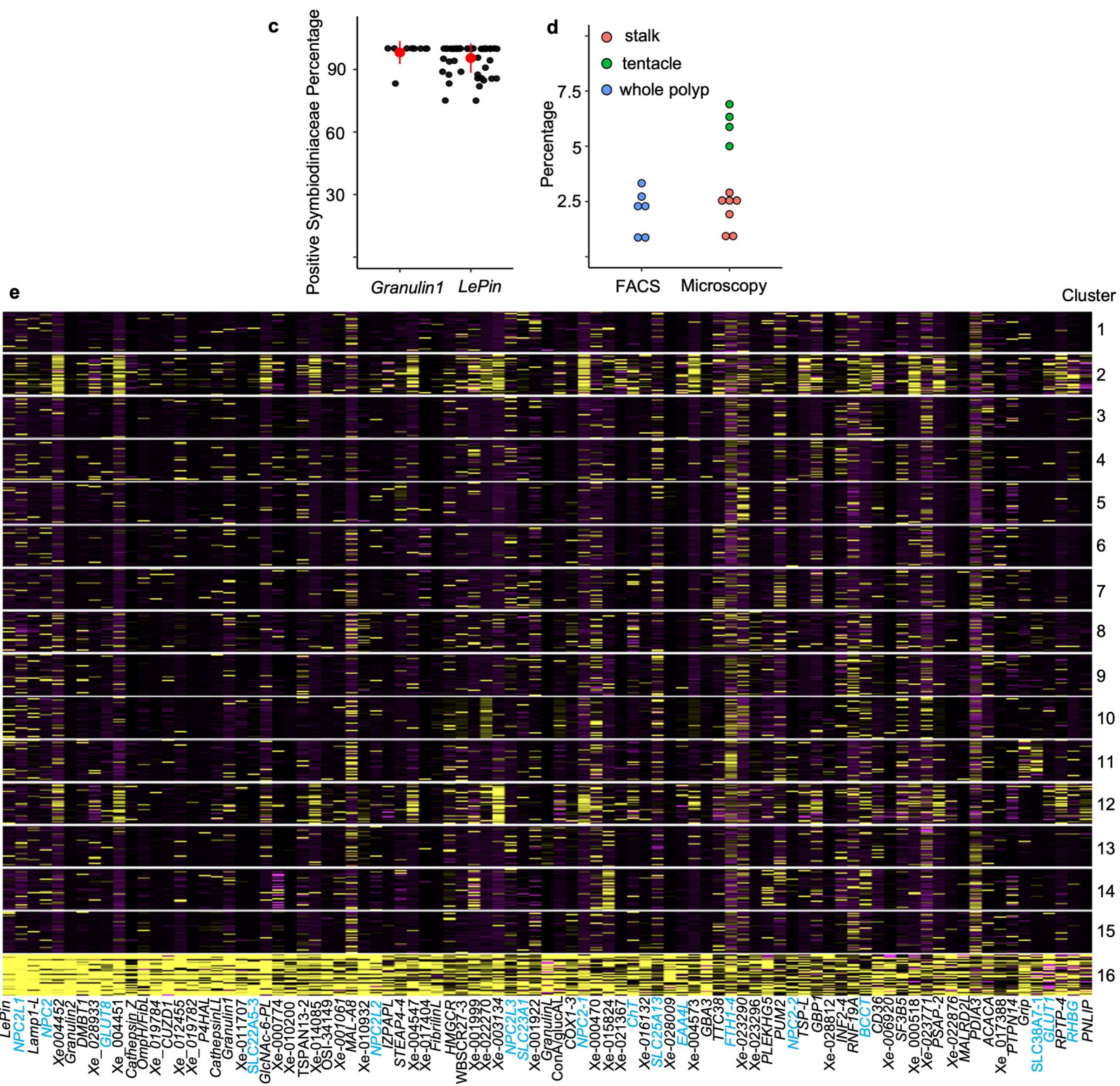

Extended Data Fig. 4 | Additional analyses for endosymbiotic cells. a, Violin plots of the expression profiles of LePin and Granulin 1 in the 16 clusters defined by scRNA-seq. Violin plots show the distribution of gene expression in each of the 16 clusters. Cell numbers in cell clusters $1-16$ are 2,$794 ; 2,704 ; 2,073$; 1,$679 ; 1,511 ; 1,374 ; 1,248 ; 1,069 ; 986 ; 923 ; 797 ; 649 ; 575 ; 321 ; 246$ and 185 , respectively. b, Ultra-sensitive chromogenic RNA ISH by RNAscope probing for Granulin 1 (left) and control (right). Positive signals are blue. Nuclei were counterstained as purple with haematoxylin. White arrows indicate algae of the Symbiodiniaceae. Six polyps from three independent experiments were used for each probe. Scale bars, $10 \mu \mathrm{m}$.c , Percentage of alga-containing cells with positive Granulin 1 or LePin signal. Each black dot stands for one section. Red dots and lines stand for mean and s.d., respectively. Six polyps from three independent experiments were used for one gene or control.d, Percentage of alga-containing cells measured by FACS and microscopy. For FACS, each dot stands for an individual polyp. Three independent experiments were performed with each experiment, using two polyps. For microscopy, each dot stands for a section analysed in three polyps. e, Heat map showing the enrichment levels of the 89 marker genes in cluster 16 among all 16 cell clusters. Transporters are highlighted in blue. 
a
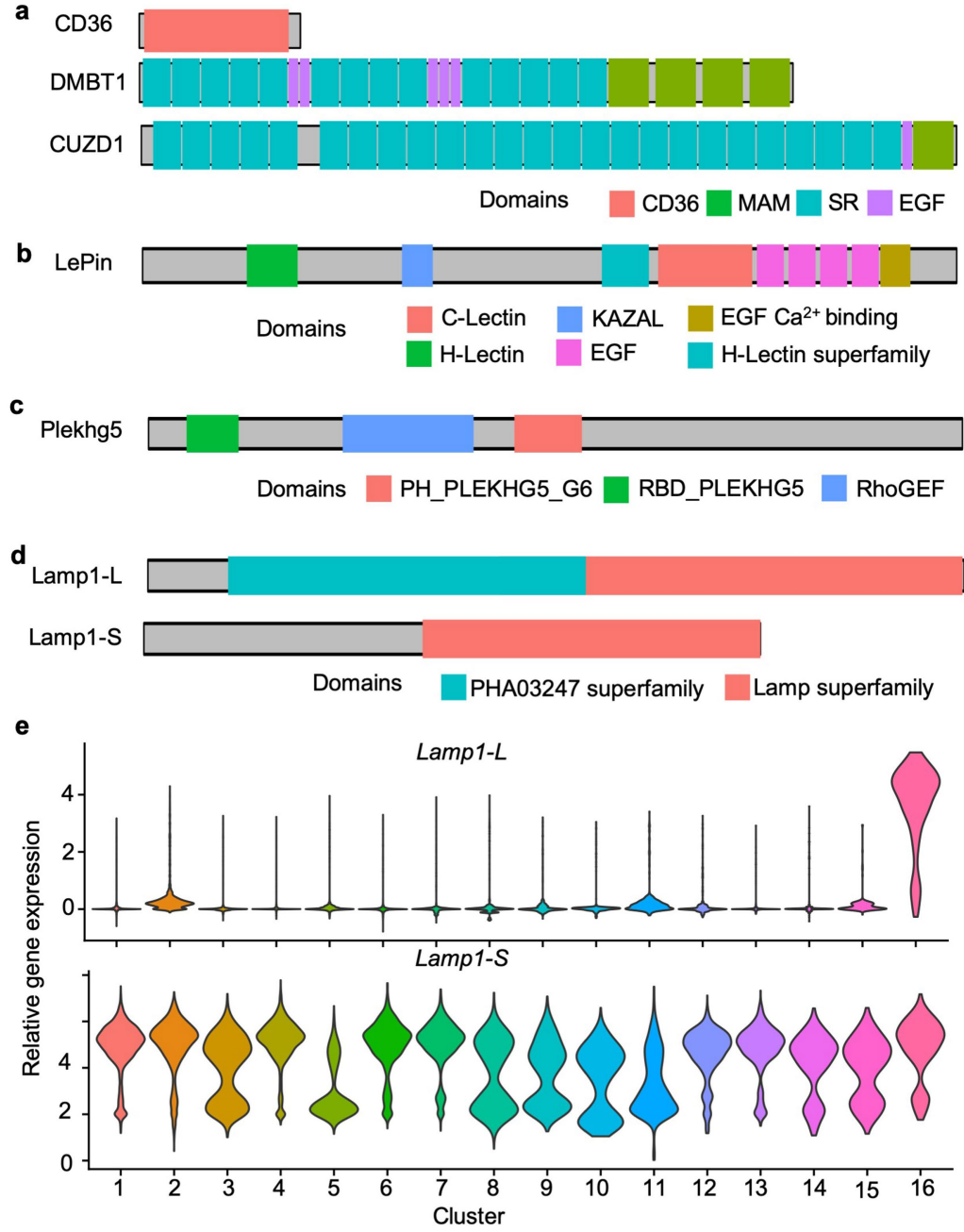

Extended Data Fig. 5 | Selected endosymbiotic markers with known domains. a, The scavenger receptors (SR) CD36, DMBT1 and CUZD1. b, LePin. c, Plekhg5.d, Lamp1-L and Lamp1-S. e, Violin plots of expression profiles of Lamp1-L and Lamp1-S in 16 clusters defined by scRNA-seq. Violin plots show the gene-expression distribution in each cluster. Cell numbers in cell clusters $1-16$ are 2,$794 ; 2,704 ; 2,073 ; 1,679 ; 1,511 ; 1,374 ; 1,248 ; 1,069 ; 986 ; 923 ; 797 ; 649 ; 575$; $321 ; 246$ and 185 , respectively. 
a

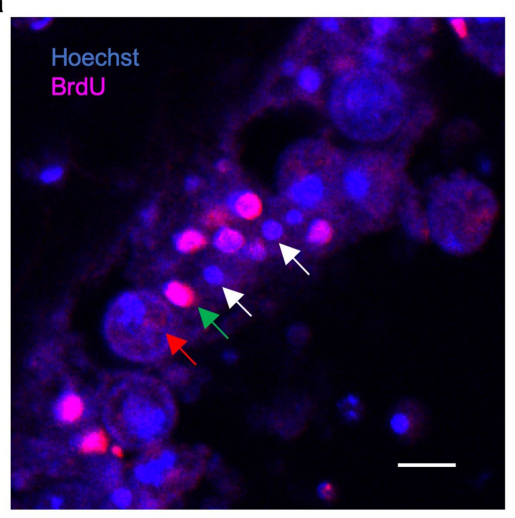

b

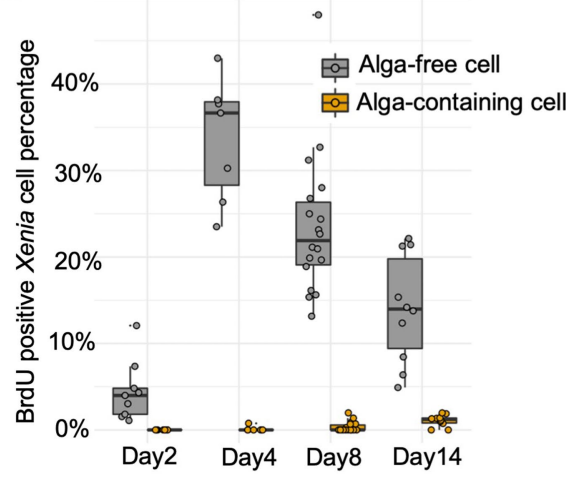

d

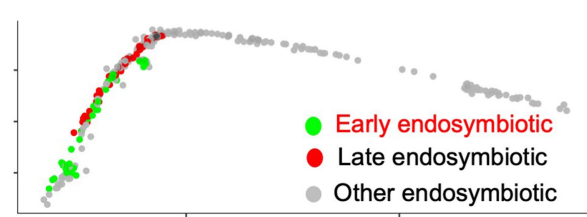

c

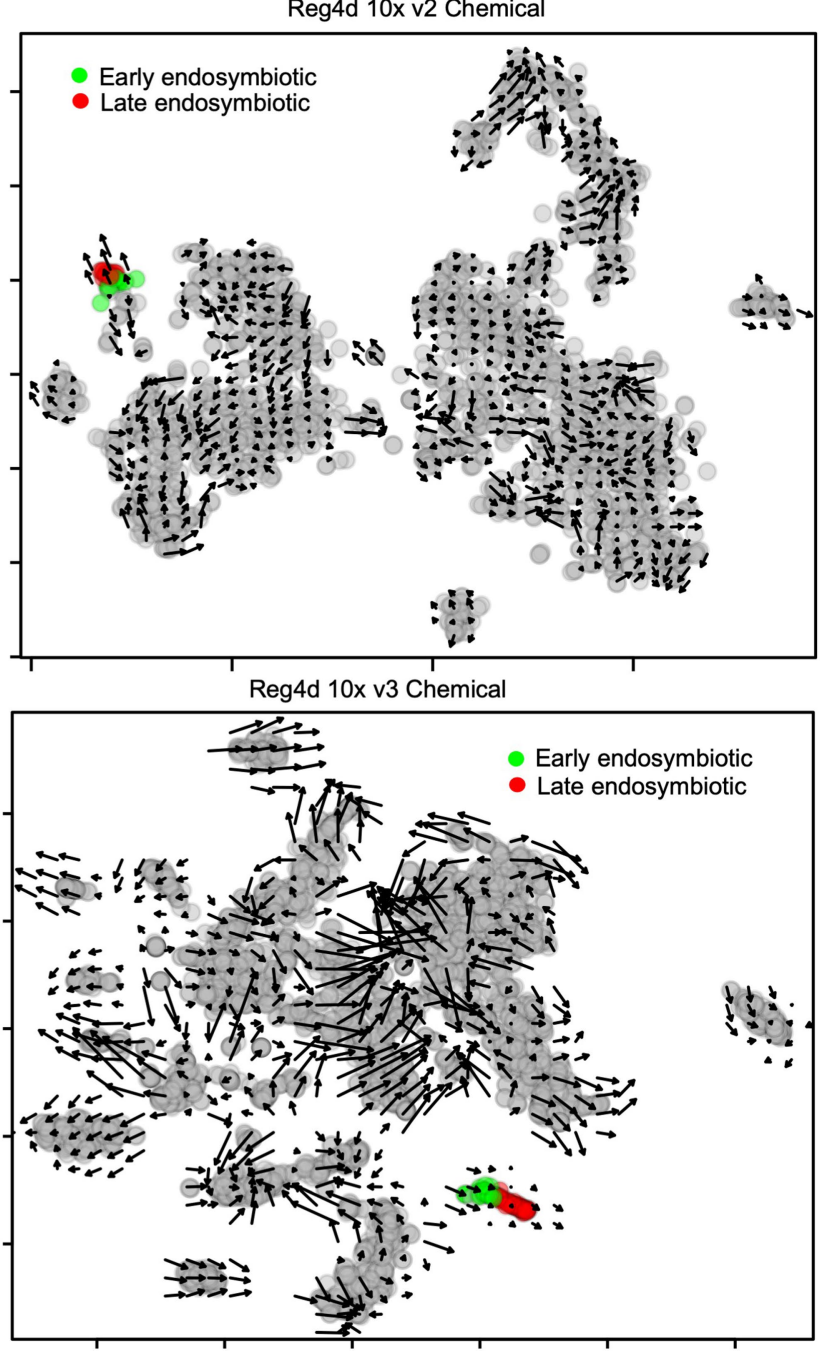

Extended Data Fig. 6 | Additional analyses of endosymbiotic cell lineage. a, A representative image of BrdU labelling (pink), overlaid with Hoechst (blue DNA stain) in a cross-section of a regenerating Xenia sp. stalk. White, red and green arrows indicate $\mathrm{BrdU}$-negative $\left(\mathrm{BrdU}^{-}\right) \mathrm{Xenia}$ nuclei, an alga and a BrdU-positive $\left(\mathrm{BrdU}^{+}\right)$Xenia nucleus juxtaposed to the alga, respectively. Three regenerating stalks were used in two independent experiments. b, Box plot. Percentages ( $y$ axis) of $\mathrm{BrdU}^{+}$Xenia cells at the indicated regeneration time points ( $x$ axis). Each dot represents data from one section. Three regenerating stalks from two independent experiments were pooled and plotted for each time point. About 7 to 18 sections were used for each group. The alga-containing proliferated Xenia cells were estimated as those with $\mathrm{BrdU}^{+}$ nucleijuxtaposed to algae. The medians are indicated as lines in the box; the upper and lower edge of the boxes represent the upper and lower quartiles, respectively. c, Velocyto analysis of the scRNA-seq data from day-4 regenerating Xenia sp. stalks. Each dot represents a cell, and arrows indicate the directions of RNA velocity. The green and red endosymbiotic cell clusters were predicted as early and late-cell states, respectively, on the basis of the directions of the arrows. d, The distribution of early (green) and late (red) endosymbiotic cells predicted by velocyto in con the pseudotime plot of all scRNA-seq data shows the start and the direction of progression of the endosymbiotic cell lineage. 
a
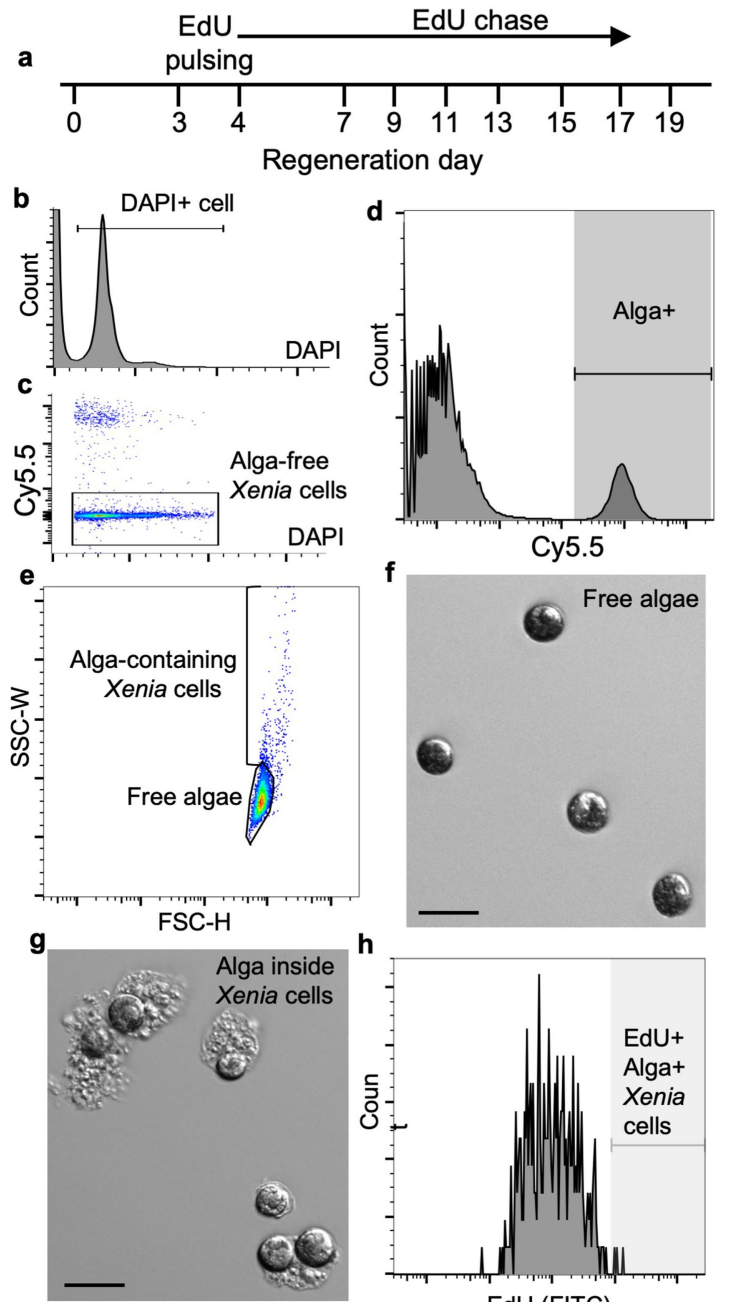

$\mathbf{h}$

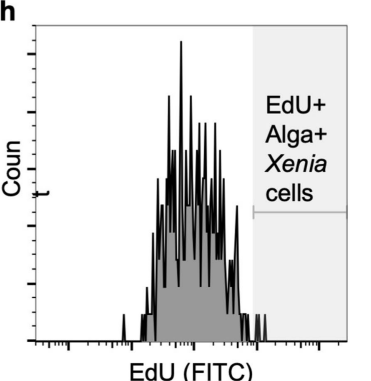

i
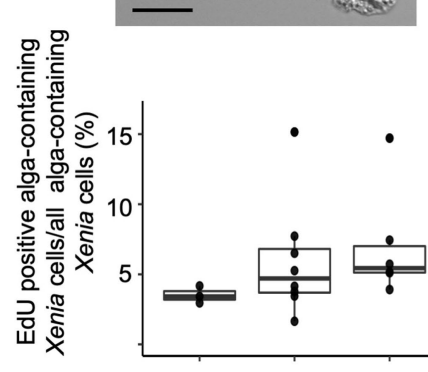

EdU (FITC)

j

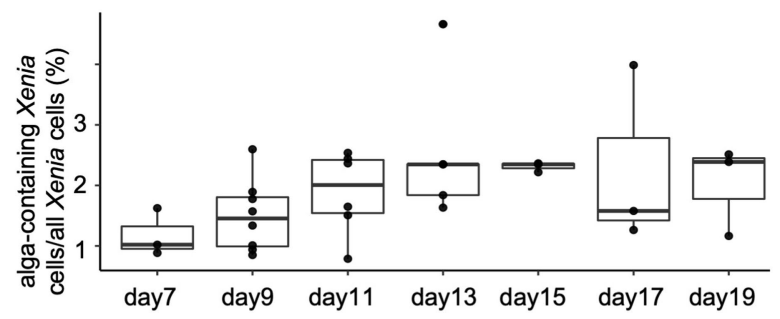

Extended Data Fig. $7 \mid$ EdU pulse-chase analysis of endosymbiotic cells. a, Pulse-chase experiments. The regeneration stalk was labelled with EdU at regeneration day 3 and day 4 . After washing out EdU, the samples were cultured, collected and analysed at the indicated days during chasing. b, Dissociated cells were processed by Click-iT to visualize EdU and stained with DAPI to label nuclei. Cells were sorting on the basis of DAPI.c, DAPI-positive cells were further sorted on the basis of Cy5.5 to estimate the number of the total alga-free Xenia cells. d, e, To estimate the number of alga-containing Xenia cells, free algae and alga-containing Xenia cells ( $\mathrm{alga}^{+}$population) were first separated from all the other Xenia cells on the basis of the Cy5.5 signal (d). The alga $^{+}$population was further separated into alga-containing Xenia cells and free algae based on the SSC and FSC signals (e).f, $\mathbf{g}$, Microscopy confirmation of free algae (f) and alga-containing Xenia cells (g) sorted in e. Scale bars, $20 \mu \mathrm{m}$. In $\mathbf{c}-\mathbf{h}$, four independent experiments were carried out. $\mathbf{h}$, The number of EdU-positive and alga-containing Xenia cells were further estimated on the basis of their strong EdU signal.i, Box plot of the percentage of EdU-positive and alga-containing Xenia cells among all alga-containing Xenia cells at the indicated days of chase.j, Box plot of the percentage of all alga-containing Xenia cells among all Xenia cells at the indicated days of chase. Each dot in $\mathbf{i}, \mathbf{j}$ stands for one regenerating sample. Day $7, n=3$ polyps; day $9, n=8$ polyps; day $11, n=6$ polyps; day $13, n=5$ polyps; day $15, n=3$ polyps; day $17, n=3$ polyps; day $19, n=3$ polyps from 2 independent experiments were assayed. The medians are indicated as lines in the boxes; the upper and lower edges of the boxes represent the upper and lower quartiles, respectively. 


\section{Article}

Extended Data Table 1 | Summary of sequencing libraries for genome assembly

a

\begin{tabular}{ccccc} 
library & read number $\left(\mathrm{M}^{*}\right)$ & read length & pair-end & data $\left(\mathrm{G}^{+}\right)$ \\
\hline 1 & 27.2 & 150 & No & 4.09 \\
2 & 19.7 & 150 & No & 2.91 \\
3 & 73.9 & 75 & No & 5.54 \\
4 & 127.4 & 150 & Yes & 38.2 \\
\hline
\end{tabular}

b

\begin{tabular}{|c|c|c|c|c|c|c|c|c|}
\hline library & read number & $\max \left(b p^{*}\right)$ & mean $(b p)$ & median (bp) & $>5 \mathrm{~kb}^{\dagger}$ & $>10 \mathrm{~kb}$ & $>20 \mathrm{~kb}$ & data $\left(\mathrm{G}^{\ddagger}\right)$ \\
\hline run1 & 819,205 & 62,624 & 4,488 & 4,341 & $38.4 \%$ & $3.5 \%$ & $0.19 \%$ & 3.68 \\
\hline run2 & 328,045 & 266,931 & 11,716 & 4,343 & $46.1 \%$ & $29.9 \%$ & $17.3 \%$ & 3.84 \\
\hline run3 & 210,985 & 310,074 & 12,677 & 5,400 & $52.4 \%$ & $32.7 \%$ & $18.3 \%$ & 2.67 \\
\hline run4 & $1,912,621$ & 143,219 & 5,228 & 4,959 & $49.5 \%$ & $7.27 \%$ & $0.37 \%$ & 10 \\
\hline
\end{tabular}

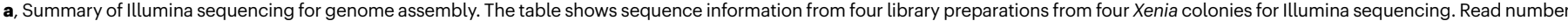

indicates the total number of reads obtained. Read length indicates the individual read length, by paired-end sequencing. Data indicate total sequence data in gigabases. $\mathrm{M}^{*}$, million;

$\mathrm{G}^{\dagger}$, gigabase.

b. Summary of Nanopore sequencing for genome assembly. Statistics of all sequence information from four different runs from four Xenia colonies of Nanopore sequencing, including maxi-

mum, mean and median read-length statistics, and the percentages of reads that have bigger sizes than the indicated number: $>5 \mathrm{~kb},>10 \mathrm{~kb}$, and $>20 \mathrm{~kb}$. $\mathrm{bp} \mathrm{p}^{*}$, base pair; $\mathrm{kb}{ }^{\dagger}, \mathrm{kilobase}$;

$G^{*}$, gigabase. 
Extended Data Table 2 | Transcriptomes for gene annotation

\begin{tabular}{cccc} 
samples & library & $\begin{array}{c}\text { read number } \\
\left(\mathrm{M}^{*}\right)\end{array}$ & data $\left(\mathrm{G}^{\dagger}\right)$ \\
\hline whole polyp & pair-end & 34.2 & 5.12 \\
Stalk & pair-end & 36.0 & 5.40 \\
Tentacle & pair-end & 39.8 & 5.97 \\
Regeneration 4d stalk & pair-end & 38.9 & 5.84 \\
Opti-Prep Iv1 & pair-end & 29.6 & 4.43 \\
Opti-Prep Iv2 & pair-end & 31.8 & 4.76 \\
Opti-Prep Iv3 & pair-end & 33.6 & 5.03 \\
Opti-Prep lv4 & pair-end & 31.1 & 4.68 \\
\hline
\end{tabular}

A summary of all the transcriptome data used for gene annotation. RNA isolated from dif-

ferent samples as indicated were used for Illumina sequencing to cover as many expressed

genes as possible. Opti-Prep, density-based separation of dissociated Xenia cells into four

different layers (Methods). Iv1, lv2, lv3, and lv4 indicate layer 1, layer 2, layer 3 and layer 4 cells,

respectively (used to make the RNA-seq libraries). $\mathrm{M}^{*}$, million; $\mathrm{G}^{+}$, gigabase. 


\section{Article}

Extended Data Table 3 | Comparisons of Xenia sp. genome assembly with the assembled genomes of the indicated and published cnidarians

\begin{tabular}{|c|c|c|c|c|}
\hline Parameter & $\begin{array}{l}\text { Xenia } \\
\text { sp. }\end{array}$ & $\begin{array}{c}\text { Exaiptasia } \\
\text { diaphana }\end{array}$ & $\begin{array}{c}\text { Nematostella } \\
\text { vectensis }\end{array}$ & $\begin{array}{c}\text { Acropora } \\
\text { digitifera }\end{array}$ \\
\hline Predicted genome size (Mb) & 197 & 260 & 329 & 420 \\
\hline Assembly size $(\mathrm{Mb})$ & 222.7 & 258 & 356 & 419 \\
\hline Total contig size $(\mathrm{Mb})$ & 222.5 & 213 & 297 & 365 \\
\hline Total contig size as $\%$ of assembly size & 99.9 & 82.5 & 83.4 & 87 \\
\hline Contig N50 (Kb) & 1,122 & 14.9 & 19.8 & 10.9 \\
\hline Scaffold N50 (Kb) & 148,322 & 440 & 472 & 191 \\
\hline Number of gene models & 29015 & 29269 & 27273 & 23668 \\
\hline Number of complete gene models & 27640 & 26658 & 13343 & 16434 \\
\hline Mean exon length $(b p)$ & 204 & 354 & 208 & 230 \\
\hline Mean intron length (bp) & 448 & 638 & 800 & 952 \\
\hline Mean protein length (number of amino acids) & 414 & 517 & 331 & 424 \\
\hline Predicted protein BUSCO $(n=978)$ completeness & $90.1 \%$ & $89.4 \%$ & $93.8 \%$ & $54.8 \%$ \\
\hline
\end{tabular}

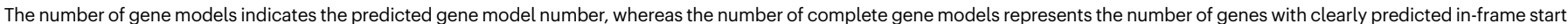

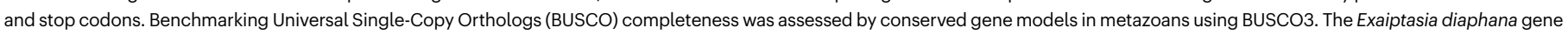
model v.1.0 was downloaded from http://aiptasia.reefgenomics.org/download/aiptasia genome.proteins.fa.gz. The Acropora digitifera gene model v.0.9 was downloaded from

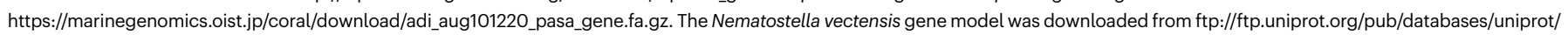
current_release/knowledgebase/reference_proteomes/Eukaryota/UP000001593_45351.fasta.gz. 


\section{natureresearch}

\section{Reporting Summary}

Nature Research wishes to improve the reproducibility of the work that we publish. This form provides structure for consistency and transparency in reporting. For further information on Nature Research policies, see Authors \& Referees and the Editorial Policy Checklist.

\section{Statistics}

For all statistical analyses, confirm that the following items are present in the figure legend, table legend, main text, or Methods section.

n/a Confirmed

$\square \bigotimes$ The exact sample size $(n)$ for each experimental group/condition, given as a discrete number and unit of measurement

$\square$ \A statement on whether measurements were taken from distinct samples or whether the same sample was measured repeatedly

The statistical test(s) used AND whether they are one- or two-sided

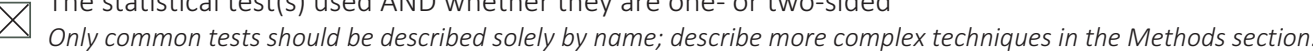

$\bigotimes \square$ A description of all covariates tested

$\square$ A description of any assumptions or corrections, such as tests of normality and adjustment for multiple comparisons

$\triangle$ A full description of the statistical parameters including central tendency (e.g. means) or other basic estimates (e.g. regression coefficient)

$\triangle$ AND variation (e.g. standard deviation) or associated estimates of uncertainty (e.g. confidence intervals)

$\square$ For null hypothesis testing, the test statistic (e.g. $F, t, r$ ) with confidence intervals, effect sizes, degrees of freedom and $P$ value noted

Give $P$ values as exact values whenever suitable.

Х $\square$ For Bayesian analysis, information on the choice of priors and Markov chain Monte Carlo settings

Х $\square$ For hierarchical and complex designs, identification of the appropriate level for tests and full reporting of outcomes

$\square$ Estimates of effect sizes (e.g. Cohen's $d$, Pearson's $r$ ), indicating how they were calculated

Our web collection on statistics for biologists contains articles on many of the points above.

\section{Software and code}

Policy information about availability of computer code

Data collection MinKNOW (v1.7.3), Albacore (v2.3.3), bcl2fastaq (v2.20.0)

Data analysis $\quad$ Canu (v1.7), Nanopolish (v0.9.2), HaploMerger2, Juicer (v1.5), Funannotate (v1.3.3), Trinity (v2.6.6), PASApipeline (v2.3.2), AUGUSTUS

(v3.2.3), GeneMark-ES Suite (v4.32), eggnog-mapper (v1.3), OrthoFinder (v2.2.7), Diamond (v0.9.21), MAFFT (v7.407), FastTree

(v2.1.10), Cell Ranger (v3.1.0), Seurat (v3.0.2), STAR (v2.5.3a), RSEM (v1.3.0), Monocle (v2.10.1), velocyto.R (v0.6), R(v3.6)

For manuscripts utilizing custom algorithms or software that are central to the research but not yet described in published literature, software must be made available to editors/reviewers. We strongly encourage code deposition in a community repository (e.g. GitHub). See the Nature Research guidelines for submitting code \& software for further information.

\section{Data}

Policy information about availability of data

All manuscripts must include a data availability statement. This statement should provide the following information, where applicable:

- Accession codes, unique identifiers, or web links for publicly available datasets

- A list of figures that have associated raw data

- A description of any restrictions on data availability

Raw sequence data for this study is available in NCBI BioProject under accession PRJNA548325. Assembled genome and gene annotation are available at http:// cmo.carnegiescience.edu/data. The scRNA analysis code is available at https://github.com/ciwemb/endosymbiosis 


\section{Field-specific reporting}

Please select the one below that is the best fit for your research. If you are not sure, read the appropriate sections before making your selection. $\bigotimes$ Life sciences $\quad \square$ Behavioural \& social sciences $\quad \square$ Ecological, evolutionary \& environmental sciences

For a reference copy of the document with all sections, see nature.com/documents/nr-reporting-summary-flat.pdf

\section{Life sciences study design}

All studies must disclose on these points even when the disclosure is negative.

Sample size No statistical methods were used to predetermine sample size. We followed standards in the biology field.

Data exclusions For single cell RNA-seq analysis, based on pre-established criteria for single-cells, in order to remove empty droplet, or droplet with potential dead cells or potential doublets, cells with UMI numbers less than 400 or mitochondria gene expression $>0.2 \%$ were filtered out. To further remove outliers, we calculated the UMI number distribution detected per cell and removed cells in the top $1 \%$ quartile.

Replication Each experiment was replicated with multiple independent animals. To draw a conclusion, at least two independent experiments were carried. All replicates were successful.

Randomization Xenia colonies or polyps were randomly chosen from the aquarium tank

Blinding Quantification of LePin signal was blinded by de-identifying samples.

\section{Reporting for specific materials, systems and methods}

We require information from authors about some types of materials, experimental systems and methods used in many studies. Here, indicate whether each material, system or method listed is relevant to your study. If you are not sure if a list item applies to your research, read the appropriate section before selecting a response.

Materials \& experimental systems

\begin{tabular}{l|l}
\hline Involved in the study \\
\hline
\end{tabular}

\begin{tabular}{l|l}
\multicolumn{2}{l}{ Methods } \\
\hline n/a & Involved in the study \\
\hline & $\square$ ChIP-seq \\
$\square$ & $\bigotimes$ Flow cytometry \\
$\square$ & $\square$ MRI-based neuroimaging
\end{tabular}

\section{Antibodies}

Antibodies used

mouse anti-BrdU antibody, from ZYMED. The catlog number is 18-0103, ZBU30 clone, Lot Number 00460071R. The dilution is $1: 200$.

Validation

The BrdU antibody was validated by a lot of studies listed in the manufactory's website: https://www.thermofisher.com/ antibody/product/BrdU-Antibody-clone-ZBU30-Monoclonal/03-3900. It has been applied in IF, IHC, FACS in Chemical, Chicken, Mouse, Rabbit and Rat. We validated it by the lack of staining when BrdU was not added into the sample.

\section{Animals and other organisms}

Policy information about studies involving animals; ARRIVE guidelines recommended for reporting animal research

Laboratory animals

Wild animals

Field-collected samples

Ethics oversight
Xenia sp. was cultured in laboratory aquarium tank. We can not yet tell their age and sex.

The Xenia sp. used in this study was originally from the wild, but we obtained it from an aquarium shop in Baltimore.

The study didn't involve samples collected from field

The study of Xenia or some other cnidaria does not yet have ethical oversight. 


\section{Plots}

Confirm that:

$\triangle$ The axis labels state the marker and fluorochrome used (e.g. CD4-FITC).

$\bigotimes$ The axis scales are clearly visible. Include numbers along axes only for bottom left plot of group (a 'group' is an analysis of identical markers).

\All plots are contour plots with outliers or pseudocolor plots.

$\bigotimes$ A numerical value for number of cells or percentage (with statistics) is provided.

\section{Methodology}

Sample preparation

Instrument

Software

Cell population abundance

Gating strategy
Xenia polyps were dissociated into single cell suspension with the same method for single cell RNA-seq. More details are provided in the method.

BD FACSAria ${ }^{\text {TM }}$ III

BD FACSDiva Software v6.1.3

All Xenia cells were divided into two population, algea-containing and algea-free, based on Cy5.5 signal. The two population have distinct Cy5.5 signal and are easy to separate. There's almost no contamination as confirmed by microscopy inspection on the sorted population. The EdU positive algea-containing population is a small population and the percentage is plotted in Extended fig $7 \mathrm{i}$

Detailed gating strategy is described in the method.

$\bigotimes$ Tick this box to confirm that a figure exemplifying the gating strategy is provided in the Supplementary Information. 